\title{
Las producciones de un alfar islámico en Almería
}

\author{
Isabel Flores Escobosa \\ María del Mar Muñoz Martín \\ Jorge Lirola Delgado
}

\section{Las circunstancias del hallazgo}

Hace aproximadamente cuatro años se procedió al derribo de un edificio situado en la actual Avenida de Pablo Iglesias, fuera del recinto fortificado de la ciudad medieval ', asistiendo al hecho una serie de personas que pronto repararon en "los numerosos cacharros que sacaban las palas excavadoras". Varios de ellos recogieron cuanto pudieron y más tarde entraron en contacto con nosotros facilitándonos el material e informándonos de haber visto allí "hasta cinco hornos de parrilla con agujeros que se veían cargados de piezas y uno de ellos contenía sólo las jarras decoradas con manganeso-esgrafiado" 2 .

Otro hecho a destacar, siempre por información oral de quienes lo vieron, es también la aparición en el lugar de restos humanos, cosa factible dado que el solar se ubica en el espacio que ocupó la necrópolis de Bāb Bâŷ̄āna ${ }^{3}$.

\section{Breves referencias urbanísticas e históricas sobre Almería}

La ciudad de Almería fue fundada por 'Abd al- Raḥmān III, quien a mediados del siglo $X$ mandó trasladar la capital desde Baŷyaāna a lo que anteriormente constituyó su arrabal y puerto. El califa cordobés, le confirió así la categoría de madina, cercándose su perímetro. Se convirtió en el puerto del califato con sede de la escuadra y a partir de ese momento madinnat alMariyya es descrita por los autores árabes como el puerto más frecuentado y activo de al-Andalus, por el que entraban las gentes venidas de Oriente y del Africa Septentrional, camino de Córdoba (TORRES BALBÁS. 1957, p. 427). Así mismo dicen que era la ciudad por excelencia de alAndalus, gran emporio industrial, comercial y marítimo; se convirtió en el lugar más visitado, al que llegaban comerciantes de todas partes en busca de fortuna y seguridad. Era la "Puerta de Oriente" y la "Llave del comercio" (MOLINA LOPEZ, 1986, p.569).

Convertida en la sede de la flota omeya y siendo uno de los puertos mediterráneos mas frecuentados generó un gran auge económico y demográfico al aumentar la población debido a los aportes de los antiguos habitantes de Bầ-

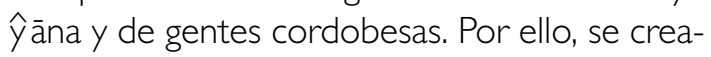
rán nuevos arrabales en torno a la Medina:

- Hacia poniente surgió el rabad al-Haw (arrabal de la Hondonada), más comercial,

\footnotetext{
I El solar está fuera del área de interés arqueológico, pero dada la importancia del lugar se había hecho una propuesta de zonificación que contemplaba su protección (GARCIA y CARA. 1992).

2 Desde aquí queremos expresar nuestro agradecimiento a quienes no dudaron en permitir el estudio de este importante material.

3 Varias excavaciones de urgencia en la zona han puesto de manifiesto la existencia de dicha necrópolis (MARTINEZ et alí, 1995).
} 
próximo al fondeadero de la Chanca, también el más poblado y rico con abundantes telares, posadas y baños.

- Hacia levante, el rabad al-Mušallà (arrabal del oratorio), que era casi tres veces superior en extensión a la antigua madina.

La fitna desencadenada en al-Andalus le afectó durante el primer tercio del siglo XI en el que se suceden las rivalidades entre gobernadores; se segregará definitivamente de Córdoba formando, primero, una Taifa eslava regida por Jayrān y Zuhayr y más tarde, andalusí, gobernada por los Banū șumādiḥ.

Aunque disminuye su protagonismo militar, prosigue su desarrollo en el aspecto económico y comercial. Ello es debido a su estabilidad política y a la mejora de las instalaciones portuarias, así como a la consolidación de su sistema defensivo. Este despegue se percibe en varios aspectos: se convierte en el refugio de grandes fortunas, posee una infraestructura "industrial" y experimenta un gran crecimiento urbano (MOLINA LOPEZ, 1990,p. 18).

Durante el dominio almorávide la ciudad continuó su desarrollo económico y comercial y recuperó, en gran parte, el militar, al instalarse de nuevo en ella la sede de la flota. Destaca como figura importante en este periodo el almirante Abū 'Abd Allāh Muhammad b. Maymūn; los Banū Maymūn eran famosos almirantes oriundos de Denia. Dicho personaje intervino abriendo el cerco de Mallorca que mantenían los genoveses, pisanos y catalanes en II I 5. Un año después reconquistó Baleares y fue nombrado oficialmente almirante de la escuadra con sede en Almería (MOLINA LOPEZ, 1986, pp.576-577).

En estos momentos al-Mariyya se abre a nuevos mercados, de modo que a las tradicionales relaciones con Africa Occidental se suman ahora las mantenidas con el Africa Negra.

Al-Rušațīi, que vivió en Almería en el momento de su mayor desarrollo económico (primera mitad del siglo XII), afirmó que: "es una de las ciudades más favorecidas de al-Andalus, conocida y famosa en otros muchos lugares" (MOLINA LOPEZ, 1986, p.569).

Muy citada en los textos es su actividad artesanal de tejidos, siendo muy conocido lo que de ella dijo al-Idrīsi: "Almería, en la época de los almorávides, era la ciudad del Islam. En ella había toda clase de industrias. Se encontraban en ella 800 telares de seda... A esta ciudad se dirigían los barcos mercantes procedentes de Alejandría y Siria. No había en todo Al-Andalus gente más adinerada que los almerienses, ni más inclinada a toda clase de comercios que ellos, vendiendo y atesorando..."(ALIDRİST, Nuzha, 562).

También es interesante destacar lo citado por Ibn Sa īid: "Almería, Málaga y Murcia se habían distinguido por los bordados de oro de cuya bella factura se maravillan los orientales cuando ven alguna pieza..."(AL-MAQQART̄, Nafh., I, 20I).

El otro material que contribuyó a la expansión económica fue el mármol procedente de la localidad de Macael, con el que se fabricaban las estelas funerarias (OCAÑA JIMÉNEZ, 1964).

Otras artesanías importantes, citadas por lbn Sa'îd, fueron el vidrio y la loza dorada: "...Se fabrica en Murcia, Almería y Málaga el cristal extraordinario y maravilloso y una loza vidriada dorada...(AL MAQQARĪ, Nafh, II, 202).

Toda la actividad comercial de exportación tenía como núcleo el puerto, con una importante infraestructura consistente en sus atarazanas, que al- 'Udrī menciona dividida en dos partes: "...en una se encuentran las embarcaciones de guerra, los pertrechos y los aparejos y en la segunda la alcaicería; había sido dispuesta de modo que cada oficio estuviera en una zona delimitada, según sus afinidades. En ella los comerciantes se encontraban seguros con sus bienes, dirigiéndose a ella la gente de todas partes." (AL-'UDRIT, p. 86).

Por el puerto llegaban productos importados de Iraq, Génova o Pisa que después se distribuían por todo al-Andalus, pagando en su aduana las tasas correspondientes, como indica 
una de las puertas de su cerca, la Puerta de la Aduana (Bāb al-Dīwān), ubicada cerca de aqueIla (LIROLA DELGADO, 1992, pp,52-53); el hecho de la reexpedición de productos orientales hacia los mercados magrebíes queda atestiguado mediante cartas de mercaderes judíos fechadas entre I I 38 y | | 4I, conservadas en la Geniza del Cairo (LOPEZ DE COCA, 1980, 93).

A todo lo anterior se sumaba un negocio lucrativo heredado de la precedente Baŷyāana: el comercio de esclavos.

La arteria principal de la ciudad atravesaba los tres arrabales uniendo la Puerta de Pechina (Bāb Baŷȳāna), con el fondeadero junto al arrabal de al-Hawḍ. Dicha puerta era la más importante de la cerca pues a ella llegaban los viajeros y mercancías de Granada, Córdoba y la Andalucía Interior (TORRES BALBAS, 1957, 44I). En sus inmediaciones se extendía el principal cementerio ciudadano: maqbarat Bāb Bâŷāana. En él fueron enterrados personajes ilustres que biografían algunos autores árabes como lbn Bașkuwāl e lbn al- Abbār, quienes aportan las fechas de $478 \mathrm{H}$ ( I08I-1082) y 485 (I092- 1093) para el enterramiento de dos trasmisores de tradiciones (TORRES BALBAS, 1985, p,269), lo que supone una ocupación del espacio funerario desde el siglo XI.

En I I47, Alfonso VII consiguió conquistar Almería mediante una acción conjunta de genoveses, pisanos, castellanos y catalanes. El asedio a la ciudad duró un par de meses contando con el reconocimiento de "Cruzada" por parte del papado. En manos cristianas permaneció por espacio de diez años en los que sufrió un colapso político y económico. Sus casas y edificios públicos se destruyeron y los barrios más prósperos quedaron arrasados.

A nivel arqueológico se corresponde con un abandono general en el que aparece un relleno alterado y revuelto con un pequeño estrato inicial de incendio; le sucede, a veces, una sedimentación estéril con pocos restos arqueológicos y termina con la ocupación superior de pisos no habitacionales en zonas concretas (GARCIA LOPEZ et alii, 1990, p, 98-99).
Tras la conquista almohade en I I 57 hubo un impulso oficial para rehabilitar la vida ciudadana: las áreas públicas de carácter políticomilitar (Alcazaba), religioso (Mezquita Mayor) y económico (Alcaicería y Atarazana). A ello se sumó el intento de recuperación poblacional. Pero no se consiguió recuperar del todo la importante actividad comercial del pasado, aunque a su puerto continuaron llegando mercancías del reino aragonés y de las repúblicas italianas. La actividad corsaria se fue recuperando y continuó en la etapa nazarí.

Se abandonaron amplias zonas anteriormente urbanizadas como queda atestiguado en algunas excavaciones efectuadas en la actual calle Álvarez de Castro, dentro del rabad alMușallà, donde se evidenció la total ausencia de restos constructivos con posterioridad a mediados del siglo XII (GARCIA LOPEZ et alii, 1990, p. 100).

En 1228 Ibn Hūd de Murcia se apoderó de la provincia formando una segunda Taifa y en I245-46 lbn al-Ahmar la anexiona al reino nazarí. En I 309 Jaime II de Aragón asedió la capital sin conseguir tomarla; el siglo XIV fue catastrófico pues al cerco se sumarán varios años de condiciones climáticas adversas que provocaron malas cosechas en la Península Ibérica, debilitando considerablemente a la población que también fue afectada por la epidemia de Peste Negra de 1348-49, lo que acarreó que aquélla se redujera muy considerablemente a partir del siglo XIV.

Cinco años después de ser conquistada por los Reyes Católicos, en I494, el viajero alemán Jerónimo Münzer la describe así: "La ciudad es triangular y tiene una muralla llena de torres; pero en el interior, desde un terremoto y después de la conquista, está tan derruida, que en muchos lugares está deshabitada y en ruinas. Antiguamente tuvo cinco mil casas habitadas. Ahora no tiene ni ochocientas. Y a cualquier forastero que allí llega con deseos de afincar, se le da casa, huertos, campos y olivos gratuitamente, para que pueda vivir holgadamente. Por esto ha de poblarse prontamente (MÜNZER, 1987, p,30). 


\section{ESTUDIO DEL MATERIAL}

\section{A.-LAS FORMAS}

\section{A.I.-Jarra}

Este grupo presenta dos apartados:

I. Con decoración: Hemos constatado varias formas:

A) Se caracteriza por un estrecho pie anular, aristado, cuerpo globular y cuello troncocónico con borde apuntado y asas recorridas por acanaladura longitudinal.

Se trata de piezas cuyas dimensiones son aproximadamente 15 centímetros de altura, 5 de base y en torno a los 9 de boca. (Fig. I, no I, 2, 3; Fig. 2 n', 4, 5, 6 y 7; Fig. 3, n |5).

Jarras del mismo tipo aparecen en Lixus (ATALLAH, 1967, planche I/I), también en Ceuta (FERNANDEZ SOTELO, 1988. Fig. 9, p. 169); en ambos lugares se señala la fineza de su ejecución. Igualmente, se documentan entre el material de Zavellá (Mallorca), en el tipo $B$, aunque aquí combinan el esgrafiado con la cuerda seca parcial (ROSSELLO PONS, 1983, nº 75 al 79); en Denia (GISBERT et alii, 1992. Fig. 17,3), y en la propia Almería, en un contexto del siglo XII (EGEA et alii, en prensa. También FLORES y MUÑOZ, 1993, nº 29, p. 95).

B) Se distingue por un cuello cilíndrico, desarrollado, cuyo extremo se curva con borde apuntado. (Fig. 2, no 8; Fig. 3, n⿳ 10 y 12 ).

Respecto al galbo, puede asignarse a este segundo grupo la figura $3, n^{\circ}$ I I que presenta hombro marcado por molduras con arranque de cuello de tendencia más cilíndrica, así como carena en la parte inferior.

No conocemos piezas semejantes en manganeso-esgrafiado aunque sí puede asimilarse a otras formas almerienses realizadas en cuerda seca parcial que se dieron como almohades (DUDA, 1970, Farbtafel, 3b).
C) Forman este grupo varias jarritas cuyo distintivo principal es el corto y ancho cuello de paredes rectas 0 abombadas con borde reentrante (Fig. 6, $n^{\circ} 23$ ), recto y marcado externamente por arista (Fig. 6, n²2).

Los cuerpos son globulares (Fig.6, $n^{\circ} 21$ y 22), o carenados, con hombros marcados (Fig. 6, $n^{\circ} 24$ y 23). Pueden llevar asitas con dos acanaladuras longitudinales y apéndices en su parte superior (Fig. 6, $n^{\circ}$ 22).

Son formas que responden a pies estrechos con anillo, semejantes a la documentada en los caños de Meca que combina la decoración de cuerda seca parcial con el manganeso, fechada entre la segunda mitad del siglo XII y la primera mitad del XIII (CAVILLA SANCHEZ-MOLERO, 1992, p. 137, Fig 17, $n^{\circ}$ 168), similar a la Fig. 6, $n^{\circ} 24$.

2. Sin decorar. También distinguimos varios tipos:

A) Vasijas de cuerpo globular, carenado en su parte media con estrecho pie anular, hombro marcado y cuello ancho cilíndrico con borde oblicuo al interior (Fig. 7, $n^{\circ} 26$ y 27). Taxonómicamente corresponde, con ligeras variantes, al tipo B del grupo manganeso-esgrafiado.

B) Jarra de cuerpo globular con marcadas acanaladuras de torno en su parte mediainferior. Fondo indicado, convexo posiblemente; cuello ancho, cilíndrico, con borde exvasado al interior (Fig. 8, $n^{\circ}$ 28).

Existe una diferencia entre los dos tipos señalados de las jarras sin decorar; la segunda es una pieza mucho más basta que generalmente se decora con trazos de manganeso o a la almagra, teniendo una gran pervivencia cronológica desde el califato hasta época nazarí.

\section{A.2.- Jarro}

También se constatan varias formas:

A) Cuerpo globular, fondo plano. Cuello alto, cilíndrico que se ensancha en su parte media 
superior. Borde marcado por moldura externa, plano u oblicuo. Marcadas estrías de torneado en el interior $y$ fuerte asa plana (Fig. 4, n० 16 y 17).

B) Jarro de boca ancha, abierta, carente de cuello, estando marcada la transición cuerpo-boca mediante estrangulamiento (Fig. $2, n^{\circ}$ 9). Estas piezas suelen tener el cuerpo piriforme y pie con ruedo.

Es una forma documentada en Zavellá (ROSELLO PONS, 1983, p. 92-102), en cuerda seca-esgrafiado, fechada en el primer tercio del siglo XIII. También en Almería, sólo en cuerda seca (DUDA, 1970. Tafel 6 a), calificada de almorávide. Denia (GISBERT ET ALII, 1992, nº 43, 44), fechado en los siglos XII-XIII y en Valencia, sólo en manganeso-esgrafiado con igual cronología a los de Zavellá (NAVARRO, 1992, Fig. 25 у р. 122).

C) Jarrito de cuerpo piriforme con pie indicado y base plana. Asa. (Fig. 6, n² 25).

Dentro de la variante jarro, se constatan dos formas cuyo elemento más distintivo es su pico vertedor. Así:

I.- Jarro de ancho cuello cilíndrico que se curva en su parte superior marcando el borde, apuntado. Presenta la particularidad de estar vidriado en verde turquesa en su interior, al igual que el pico vertedor (Fig. 3, n० |3).

2.- Jarro de cuerpo globular y cuello de paredes abiertas (Fig. 8, n 30). Se trata de una forma repertoriada entre la cerámica de Meca (CAVILLA, 1992. p. 141. n 229), y Mértola (TORRES et alii. 1987 (199I), p. 529), fechado en el siglo XII.

\section{A.3.- Ataifor}

A) Responde al tipo II, variante I de Roselló (ROSELLO, 1978. Fig. 7, tipo Ila). Su distintivo esencial es la pestaña vertical que forma el borde con labio engrosado al exterior y redondeado (Fig. 9, n 32).
Es una forma ampliamente documentada en el siglo XII que se mantiene con variantes hasta finales del periodo nazarí (FLORES Y MUÑOZ, 1995, p. 256).

B) Se caracteriza por presentar el cuerpo carenado con borde más o menos exvasado al exterior. Pie con ruedo (Fig. 9, no 33 y 34).

La $n^{\circ} 34$ presenta una forma similar a la pieza aparecida en Denia y decorada en cuerda seca total (AZUAR, 1989, p. 49, Fig. 20) si bien la nuestra muestra una carena más acusada.

Es curioso el hecho de que la decoración estampillada que aparece en nuestra pieza se asocia en otros registros a la forma $A$, concretamente en Mértola, con una cronología del siglo XII (TORRES et alii, 1987 (1991), pp. 521-522).

\section{A.4.- Redoma}

Encontramos varios tipos:

A) Pieza de cuerpo globular con arista marcada en su base. Pie anular, oblicuo, también aristado (Fig. 5, n²0).

Una pieza similar se encuentra en Mértola, fechada en los siglos XI-XII (TORRES, 1987, $n^{\circ} 80$ ).

B) Vasija de cuerpo globular. Cuello angosto desarrollado y moldurado en la parte superior. Borde engrosado al exterior y también moldurado. Asa que arranca de la zona media del cuello. (Fig. I0, n⿳4十).

C) Vasija de cuerpo globular con base plana, indicada. Cuello estrecho, moldurado y boca con pellizco. Asa robusta entre la parte superior del cuello y media del galbo (Fig. 10, n⿳40).

Los tipos B y C se separan claramente de lo que son las redomas nazaríes (FLORES Y MUÑOZ, 1995. Fig, 19.1 I). Ambos tipos están documentados en el siglo XII (AZUAR, 1986. Fig. I, p. (87). 


\section{A.5.-Tapaderas}

También se documentan varios tipos:

A) Troncocónica, con cama para encajar sobre el objeto que cubre, si bien aparecen de distinto tamaño y pequeñas variantes formales: La Fig I0, $n^{\circ} 35$ a presenta el asidero macizo, mientras que en la Fig. I0, n 36, aparece cóncavo y presenta, además, aristamiento en el cuerpo. Es un tipo constatado en el siglo XII (ACIÉN et alii, 199| (1995), nº 65I).

B) Discal, con borde apuntado y base plana. Asidero central cóncavo. (Fig. 10, n 39). Se trata de una forma constatada desde momentos muy tempranos, de entronque con el mundo tardorromano, pero ampliamente difundidas al servir de cubrición las grandes vasijas estampilladas, como es el caso que nos ocupa.

C) Cóncavas, con base plana o ligeramente cóncava, pedúnculo central. Son formas para engastar en el interior de los cuellos (Fig. 10, n 37 y 38), y también comienzan a fecharse desde momentos tempranos.

\section{A.6.- Anafres}

Varios tipos:

A) Pieza de base plana con cenicero cilíndrico y abertura cuadrada. Parrilla de rollos sostenidos por vástago central. Cuerpo troncocónico con orificios de aireación. Borde ligeramente oblicuo en el interior, con apéndices. Dos asas (Fig. II, n 42). Es un tipo constatado ya en el siglo XI (ACIEN et alii, 199। (1995) n 736), pero con pervivencia posterior.

B) Anafre con pie indicado, cenicero con abertura cuadrada, parrilla cupular con orificio central y otros laterales. Cuerpo superior troncocónico con canales de aireación. Asas (Fig. I I, n 43). La parrilla cupular no es un signo de modernidad puesto que aparecen en momentos tempranos (ACIEN et alii, |991 (1995) n $n^{\circ} 727$ y 728 ).
Su pequeño tamaño está en consonancia con las marmitas también encontradas en este registro.

C) Denominamos esta pieza Anafre de cámara única, por similitud con otros aparecidos en Denia (GISBERT et alii, 1992, pp. 96-97 y fig 23, nº I y 2).

Presenta cuerpo cilíndrico ensanchado en su parte superior con apéndices que lo aislan del suelo. Borde también con apéndices, proyectado al exterior, de sección cuadrada y ligeramente exvasado al interior. Asas en forma de muñones (Fig. 8, n⿳31).

Al ser una pieza que no ha estado utilizada no podemos precisar si sus paredes están o no quemadas, pero también podría tratarse de un pequeño brasero o de un elemento contenedor de fuego que mantuviese caliente cierto tipo de comida como parecen indicar los apéndices del borde, sobre los que descansaría otra pieza.

\section{A.7.- Marmitas}

Todas responden a un mismo tipo caracterizado sobre todo por la pared ligeramente curva y entrante en su terminación. Borde oblicuo internamente, marcándose al exterior mediante incisión. Bases planas o ligeramente cóncavas y asitas alternando con pequeños muñones (Fig. 10, n 44, 45, 46 y 47).

Son un recuerdo de las marmitas califales hechas a mano, con distintos tamaños, lo que nos lleva a pensar en su utilización de servicio directo.

\section{A.8.- Brasero}

Pieza de pared curva, gallonada al exterior. Borde plano y fondo también plano con apliques que lo aislan del suelo. (Fig. 12, n 48).

Una pieza similar se encuentra en Valencia, fechada a fines del siglo XII o primer tercio del S. XIII (COLL et alii, 1988, p. 69, n 19). 


\section{A.9.-Candiles}

Dos tipos:

A) De cazoleta y piquera (Fig. 12, n 49), con alguna variante: La fig. $12, n^{\circ} 50$ presenta el cuello estrecho y la boca en forma de seta.

B) De pie alto (Fig. 12, $n^{\circ} 51$ ). Presenta un gran desarrollo y elevación de la peana que suele acompañar a un fuste bajo sin molduras.

La aparición de ambos tipos juntos ya se ha constatado en Almería, en un contexto del siglo XII (GARCíA et alii, 1992, p. 24)

\section{A. 10. Taza}

Vasija de cuerpo globular con borde exvasado al interior. Asas con apéndice (Fig. 8, $n^{\circ}$ 29). Es una forma encontrada entre los materiales de Zavellá y fechada en el primer tercio del siglo XIII (ROSSELLÓ PONS, 1983, p. 109).

\section{A.I I. Alcadafe}

Vasija de fondo plano, paredes troncocónicas y borde engrosado, moldurado al exterior (Fig. I 3, n 52). Es una pieza altamente representada en Almería desde momentos tempranos a tardíos (FLORES et alii, 1993, p.I57 y fig 4, p. 164).

\section{A. 12. Maqueta arquitectónica}

Pieza de base plana, cuerpo rectangular y borde plano moldurado sobre el que encajaría la parte superior (Fig. 13, n 53). Como ya se ha señalado, estas piezas pudieron servir como piletas de ablución (NAVARRO Y JIMÉNEZ, 1995, p.208 y nota 9).

\section{A. 13. Reposatinajas}

Pieza de cuerpo cilíndrico, borde de sección cuadrada, reposadero plano y pico vertedor (Fig. 14, n 54).

\section{A. I4. Fuente-surtidor}

Pieza con cuerpo en forma de casquete esférico, borde plano y abertura circular en la base (Fig. 14. n 55).

La adscripción a este tipo la hacemos por el conocimiento de piezas con tal fin (MARINETTO y FLORES I99। (1995), pp. 178-183 y n 1449, 7319), aunque también podría tratarse de un molde para realizar jarras/os (Fig. I5b), que más tarde recibirían el dorado, como alguno encontrado en Mértola, fechado en el siglo XII (TORRES, 1987, $n^{\circ} 75$ ), y en la propia Almería (FLORES et alii, 1989. Figs. I y 2).

\section{A. I5. Cántara}

Vasija con cuerpo de tendencia cilíndrica, base plana y cuello cilíndrico con borde engrosado y marcado al exterior, exvasado al interior. Asas planas y robustas (Fig. 15a)

\section{A.16. Especiero}

Compuesto de dos piezas:

I.- Pequeño platito de pie anular, pared carenada y borde exvasado al exterior (Fig. 9, ${ }^{\circ}$ 35 b). Corresponde a la forma B del grupo ataifor en este registro.

2.- Tapadera troncocónica y cama que engasta en el interior del platito. Asidero central (Fig. 35 a).

Aparecieron in situ, una sobre otra. Dato curioso es que el platito presenta en el anillo del ruedo un pequeño orificio que podría ser para sujetar ambas cosas mediante un hilo metálico.

\section{A.17. Tinajas}

Los fragmentos responden a un mismo tipo morfológico:

Bordes planos moldurados, cuellos anchos, cilíndricos. Cuerpos globulares, sobre todo en su parte superior $y$ fondos planos. 


\section{B.- LAS TÉCNICAS}

Hay que subrayar, ante todo, el excelente estado de conservación de este material que, como ya hemos mencionado, se encontró dentro de los propios hornos.

En líneas generales estas piezas presentan una buena manufactura, siempre a torno, aunque con matices diferenciadores; se observa un perfecto torneado en las jarras decoradas con manganeso y esgrafiado, así como en las de cuerda seca parcial; algunas de éstas últimas presentan paredes "de cascarón de huevo" (Fig. $6, n^{\circ} 22$ y 23). Igualmente sucede con algunas jarras sin decorar (Fig. 7, n² 26 y 27).

Por el contrario, las decoradas con cuerda seca total son mucho más bastas en su ejecución y aparecen pasadas de horno (Fig. 4, n 16 y 17; Fig. $5, n^{\circ} 20$. Igualmente se puede decir de la Fig. $\left.8, n^{\circ} 28\right)$.

En lo que respecta a las piezas con uso culinario, como son los anafres y las marmitas, están elaboradas con una arcilla roja refractaria también de fina ejecución.

En lo referido a las técnicas decorativas encontramos:

I.- Manganeso y esgrafiado. En este contexto hay una gran perfección de la técnica pues los motivos decorativos están perfectamente delimitados por las líneas incisas y no hay en ellas intrusión del manganeso.

La aparición de un fragmento sólo en barro (Fig. 3, no 15) nos lleva a pensar en su ejecución mediante dos cocciones, una con el barro y el esgrafiado pues, evidentemente el fragmento lo confirma, y otra con la pintura en manganeso.

2.- Cuerda Seca. Hay una deficiencia en su ejecución y generalmente el vidriado sobrepasa la línea del manganeso. También suelen aparecer rehervidas.

3.- En lo referido a las cubiertas vidriadas, aparecen tanto al exterior como en el inte- rior, utilizándose las tonalidades meladoamarillo (platito, peana de candil) meladoverdoso (candil de piquera) y verde turquesa (jarro con pico vertedor o platos).

\section{C.- LAS DECORACIONES}

En líneas generales, se ejecutan de forma rápida, pero segura en el dibujo, siendo más importante la composición general que el detallismo.

Las decoraciones realizadas en manganeso-esgrafiado, corresponden a formas cerradas, apareciendo la superficie del objeto cerámico dividida en bandas horizontales. Destaca, por la mayor profusión y delicadeza del esgrafiado, la que circunda la boca de la jarra/o que no se interrumpe, mientras el resto de ellas quedan cortadas en el espacio de las asas. Además, sólo presentan el esgrafiado en pequeños trazos.

La temática de estas piezas es básicamente epigráfica, que estudiaremos más adelante, ocupando incluso el interior de los cuellos (Fig. I, 2 y 3$)$.

También encontramos temas fitomorfos, como son las palmetas unidas por su ápice (Fig.3, $n^{\circ}$ 12), cuya nervadura se realiza mediante el esgrafiado, tratadas como elemento unitario; es un tema conocido en la loza dorada y esgrafiada de al-Andalus, concretamente la encontrada en Murcia y fechada en la primera mitad del siglo XII (NAVARRO PALAZÓN, 1987).

Con estos fragmentos se confirma el paralelismo entre los temas decorativos del manganeso-esgrafiado y dorado esgrafiado, por otro lado, aparecidos en lugares donde ha habido producción de loza dorada que en el caso de Almería se confirma por las fuentes árabes, ya mencionadas, y los fragmentos hallados en la Avenida de Pablo Iglesias (Lám $V$ ), a pocos metros de los que se mencionan en este estudio, dentro de la misma zona industrial.

Los temas geométricos se forman en función de la propia epigrafía puesto que ésta da lugar en las bandas a espacios vacíos que se 
rellenan con espirales (Fig. I, nI, 3. Fig. 3, n I I0), semicírculos con punto en su interior (Fig. 2, $n^{\circ}$ 5. Fig. 3, $n^{\circ}$ 15), líneas inclinadas (Fig. 2, n⿳9 9), o reticula (Fig. $2, n^{\circ} \mid$ y 6 y Fig. $3, n^{\circ} \mid 3$ ).

Otras veces, estos temas geométricos ocupan la banda principal en torno al cuello, siendo el más representado las líneas quebradas que van formando triángulos con espirales en su interior (Fig. 2. n 8 y 9). Son símbolos de agua asociados a las formas utilizadas a tal fin.

En algún caso, el cuello puede aparecer decorado con un tema unitario geométrico del damero con punto en su interior, unidos por aspas esgrafiadas (Fig. $2, n^{\circ} 5$ ), que puede interrumpirse en el espacio de las asas (Fig. 2, n 8).

Por lo que respecta a las decoraciones en cuerda seca, aparece la representación zoomorfa (Fig. 5, n²0), con una tendencia ornamental sobre la naturalista; en el caso que nos ocupa, se trata de un ave de perfil con las alas y cola plegadas, perfilada por el trazo del manganeso y rellena de esmalte blanco, del que sólo se destaca el ojo y el penacho, ambos en verde. Encerrado en un círculo propio de la estética bizantina y sasánida, adoptado también en los tejidos almorávides. Debe tratarse de un halcón, que suele simbolizar la inmortalidad.

Otros temás de carácter geométrico/vegetal son las gotas, tanto en cuerda seca total (Fig. 4, n' 16), como parcial (Fig. 6, n⿳222) y hojas acorazonadas formando un cordón (Fig. 4, n 17).

Los llamados losanges (Fig 4, n⿳ 17 y I8) y los rombos con punto en su interior y rodeados de puntitos forman parte de una temática muy característica en Almería (Fig. 6, n²4).

En alguna pieza, el elemento decorativo (gotas) carece de perfilamiento con manganeso (Fig. 6, n²5).

Otra manera de ornamentar estas piezas es a base de una decoración pintada, que puede aplicarse tanto a pincel -caso de las jarritas donde se combina con el esgrafiado- o por impresión digital como es el caso de la Fig. 8, $n^{\circ}$ 31 , que se decora a la almagra. De la misma manera, la pieza considerada como maqueta (Fig. I3, n⿳53), se pinta a la almagra, de manera uniforme en el borde, quedando pequeñas gotas en las paredes por haber salpicado.

La decoración incisa está representada por las líneas onduladas, en lo que se llama "a peine" (Fig. 13, n⿳ 52), o anchas líneas que componen varios campos geométricos. Así la fig. 13, n 53, en cuyos lados mayores alterna el damero con las líneas quebradas.

Las decoraciones estampilladas pueden aparecer sin vidriado, como el caso de la mayoría que nos ocupa, propia de las grandes vasijas de almacenamiento donde se combinan diversos temas: epigráficos (que se estudian aparte); fitomorfos, como la roseta formando un círculo (Fig. 13, n 39), o pequeñas rosetas formando bandas de separación para otros temas (Fig. 16, n 57, 59,60,61), hojas trilobuladas y polilobuladas envueltas en un tallo (Fig. 14, $n^{\circ} 54$. Fig. $16, n^{\circ} 57$ y 64), finos tallos acabados en palmetas (Fig. 16, n 58 y 6I), y palmetas (Fig. 16, n $61)$. Geométricos, como pequeños círculos concéntricos (Fig. 16, n 58, 60, 63 y 64). Estos últimos aparecen también en formas abiertas como el ataifor de la Fig. 9, n 34, aún sin vidriar.

En las vasijas de almacenamiento se combinan además los motivos excisos (fig. 16, n 62 y 63. Fig. 14, n54), y los apliques pásticos que forman columnas (Fig. 16, n 64), o arcos (Fig. 16, $\left.n^{\circ} 63\right)$.

Decoración a molde, donde se combina un tema geométrico -el lazo-, con hojas trilobuladas (Fig. 13, n $n^{\circ}$ 55), o la estrella de ocho puntas en el fondo del brasero (Fig. 12, n⿳48).

\section{LA DECORACIÓN CALIGRÁFICA}

La caligrafía está considerada, en general, como la más noble de las artes dentro de la cultura árabe-islámica medieval. El valor de la escritura en esta cultura rebasa lo puramente decorativo y ornamental; sin renunciar a su dimensión visual, con sus bellos trazos, sino que, por el contrario, aprovechándola y desarrollándola, trasciende y se convierte, en último término, en una 
forma de arabizar e islamizar el contexto en el que aparece. A este respecto, no hemos de olvidar el carácter sagrado que la lengua árabe tiene para un musulmán. La palabra escrita se convierte así en un elemento simbólico de gran fuerza, máxime ante el gran poder evocador que la lengua árabe tiene al ser ésta una lengua muy connotativa. A través de la palabra escrita, el más significativo de los signos distintivos del Islam, de una forma simple y directa, se islamiza la realidad circundante. Para ello se eligen tanto locuciones de cierta extensión, con frecuencia citas coránicas, como expresiones cortas y repetitivas.

En el presente caso, como contenido textual de las inscripciones nos encontramos con fórmulas breves, formadas únicamente por un vocablo o, a lo sumo, dos (caso de las $n^{\circ} 62$ y 63), que se repite de forma continua. Como es habitual, se trata de términos con una fuerte carga semántica que expresan buenos deseos para el propietario, sin que llegue a explicitarse la expresión li-șahhibi-hi (para su dueño) como aparece en otros contextos (OCAÑA, 1945 y FLURY, 1924). Los vocablos que aparecen en las cerámicas estudiadas son: as-salāma $\left(n^{\circ} 1,2,4\right.$, 6, 7, 13 y I4), al-yumn ( $n^{\circ} 1,2,3,5,7,8,10,11$ y I5), yumn, sin artículo ( $\left.n^{\circ} 1\right)$, baraka $\left(n^{\circ} 20\right.$ y 58), baraka kāmila (n 63), at-tawfīa ( $n^{\circ} 59$ y 60) y tawakk.l bi-kum (n०63).

Se trata, en todos los casos, de leyendas con un sentido protector o profiláctico. Veamos y analicemos a continuación su contenido semántico.

El vocablo as-salāma, con el significado de "la salud, el bienestar, la integridad o la seguridad", deriva de una raíz con unas fuertes connotaciones en la cultura árabe-islámica, pues, aparte de ser muy utilizada en el lenguaje cotidiano en saludos y despedidas, de ella misma deriva la palabra islām.

El término al-yumn, que no aparece como tal en el Corán, es el que suele repetirse con mayor frecuencia en este tipo de inscripciones. De hecho, en las estudiadas es el que más aparece. Aunque suele traducirse frecuentemente por "felicidad", su contenido semántico es mucho más rico, pues también puede significar "buena suerte". La raíz y-m-n contiene las ideas de "derecha", "suerte o buen augurio" y "felicidad o prosperidad".

La palabra baraka hace referencia a una bendición o fuerza benéfica de origen divino que permite conseguir beneficios, tanto materiales como espirituales, y que es enviada por Dios a los hombres. El hecho de que los santones, al igual que los profetas, puedan transmitir baraka tanto en vida como después de muertos favoreció una religiosidad popular que extendió el culto a los santones, en cuanto que poseedores y transmisores de esa fuerza benéfica. Con frecuencia acompaña a este sustantivo un adjetivo como al-kāmila (completa) o aš-šāmila (general, entera).

El vocablo at-tawfía puede traducirse por "el éxito (que da Dios), la ayuda (divina), la prosperidad, la suerte". El verbo tiene, entre otros sentidos, dar el éxito. Creemos que se podría traducir por "la buena estrella", en relación con el símbolo (la estrella de ocho puntas) que le acompaña en algunos casos. Aparece en el Corán en dos aleyas: IV, 62 y XI, 88; en esta última se dice: "... Mi éxito no depende sino de Dios. En Él confío y a Él me vuelvo arrepentido".

La palabra tawakkul (confianza [en Dios]) es utilizada con frecuencia en cerámica orientales durante los siglos IX-XII (BARCELÓ, 1990, I40). El verbo tawakkala, con el sentido de "confiar o ponerse en manos de Dios", es muy utilizado en el Corán, rigiendo la partícula "alà seguida de Allāh, pero no de la preposición bi, como aparece aquí; en este último caso el sentido que tiene es el de "responder de algo, asumir o encargarse".

Las leyendas detalladas, siguiendo la numeración de las piezas, son las siguientes:

I) Banda superior del cuello:

$$
\text { as-Salāma }
$$

El vocablo aparece repetido tres veces, en caracteres cúficos simples esgrafiados. La tă marbüta aparece con trazo vertical elevado para igualar a las dos lām y las dos alif. 
En una de ellas, la final, falta la tă marbüța . Las letras aparecen sin los trazos horizontales que las traban.

Banda inferior del cuello:

$$
\text { al-yumn }
$$

Se repite, en grafía cursiva defectuosa dispar, la palabra en seis ocasiones, tres en cada lado, siendo la más legible la quinta, que aparece incluso vocalizada, aunque con los puntos diacríticos de la ya' desplazados hacia la izquierda.

Parte superior del cuerpo:

$$
\text { يمن yumn }
$$

Aparece sin artículo e invertido en relación con el resto de las leyendas, repetido dos veces, una por cada lado. Las letras, pintadas, no aparecen trabadas, jugándose con cierta simetría en torno a la forma esférica de la letra mìm, en forma próxima a constituir una seudo-caligrafía.

Parte central del cuerpo:

$$
\text { al-yumn }
$$

Aparece pintado en caracteres cursivos bastante legibles. El término es repetido seis veces, tres por cada lado.

Interior:

$$
\text { al-yumn }
$$

Aparece sin trabazón entre algunas letras, repetida dos veces y seguramente una tercera en uno de los fragmentos no conservados.

2) Se observan dos bandas epigráficas:

En el cuello, debajo de una seudo-caligrafía:

$$
\text { al-yumn }
$$

En letra cursiva estilizada, con puntos diacríticos mal colocados, con función orna- mental. La banda epigráfica queda interrumpida en las asas, como en el resto de los casos.

En el cuerpo:

$$
\text { as-salāma }
$$

El vocablo es repetido cuatro veces, dos por cada lado, quedando la última de ambos lados incompleta. Llama la atención los trazos puntiagudos inclinados hacia la izquierda con pronunciada inclinación de la sin y los círculos que decoran las uniones de algunas letras.

3)

$$
\text { al-yumn }
$$

Aparece tanto en la banda superior del cuello, en letra cursiva estilizada próxima a una seudo-caligrafía, como en el borde interior de la jarra. En este último caso, pintado en caracteres cúficos simples y repetido dos veces, aunque serían cuatro probablemente si se hubiera conservado completa. En la banda superior externa se repite el término esgrafiado. En la franja inferior del cuello se repiten lazos seudo-epigráficos que juegan con las letras mìm y $\mathrm{fa}^{\prime} / q a \bar{f}$.

4) En la banda superior del cuello:

$$
\text { as-salāma }
$$

En el interior aparece un adorno formado por la unión de dos yumn, sin artículo, en espejo, que comparten la misma letra nūn. Constituye un claro ejemplo de una caligrafía que pierde su valor semántico quedando únicamente su valor puramente decorativo, hasta llegar a adquirir una forma casi irreconocible desde el punto de vista de la caligrafía.

5)

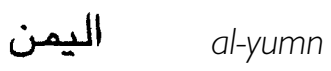

Repetido en el borde superior del cuello seis veces, esgrafiado en letra cursiva estilizada, muy próxima a una seudo-epigrafía, al imitar las formas circulares decorativas. 
6)

as-salàma

Aparece en el borde superior, esgrafiado, en cúfico simple, con las letras sin trabar. En el interior, aparecen parte de los trazos aislados de las letras yă y nūn de la palabra alyumn, palabra que no aparece completa por la fragmentación de la pieza.

7) En el borde superior externo:

$$
\text { as-salāma }
$$

En letra cúfica de traza simple.

En el interior:

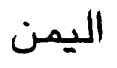

al-yumn

Con las letras sin trabar.

8) La palabra que aparece en el interior podría ser una deformación de al-yumn.

10)

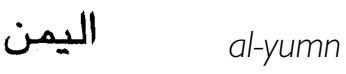

Aparece, repetidas varias veces, tanto en la banda superior del cuello, esgrafiada, como en la banda inferior del cuello, pintada. La realización corrió a cargo de alguien que no dominaba la grafía árabe, pues las letras aparecen mal trazadas y defectuosamente trabadas, adoptando, incluso, formas distintas; quien las realizó las veía más como dibujos que como palabras.

II)

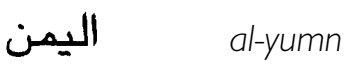

La palabra aparece pintada en grafía cursiva y repetida varias veces en la franja central de la vasija, aunque tan sólo se conserve un fragmento. Parte de un yumn, probablemente sin artículo e invertido en relación al resto de inscripciones, y en fase de convertirse en una seudo-caligrafía
13) En la banda superior del cuello:

$$
\text { as-salāma }
$$

Esgrafiado en letra cúfica.

En la banda inferior del cuello podría tratarse de un muy deformado al-yumn.

14) Parte central del cuerpo:

$$
\text { as-salāma }
$$

Pintado en grafía cúfica y repetido varias veces. Las letras no aparecen trabadas, aunque haya sido trazada una línea contínua que ha servido de guía y que trata de suplir la deficiencia.

15)

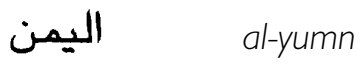

Esgrafiado, aún sin pintar, en grafía cursiva estilizada con formas redondeadas que siguen el ritmo de la decoración, como en los casos $n^{\circ} 5$ y 10.

20)

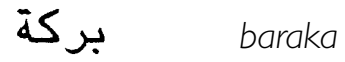

La leyenda, escrita en cúfico simple, aparece repetida dos veces. Los trazos verticales de las letras b $\vec{a}^{\vec{\prime}}$ y tă marbüta aparecen elevados para igualarlos con la kấf, como era frecuente.

21), 23) y 24) Con decoración seudo-caligráfica.

57) En este fragmento aparecen los restos de dos letras de trazo alto y entre ambas otra, sin que se vean los trazos inferiores y se pueda, por tanto, precisar de qué letras se trata.

58)

... كة.....ka ... (Seguramente baraka)

Escritura cúfica simple, aunque no se observan los rematen de las letras por lo fragmentado de la inscripción. 
59)

$$
\text { at-tawfía }
$$

Leyenda estampillada en escritura cúfica, aunque con puntos diacríticos, más bien de adorno al no estar bien dispuestos en algunos casos, repetida continuamente a lo largo de toda la banda. Destaca la prolongación del trazo vertical de la yä para igualar a los trazos de el alify la lām iniciales y la qā́f final. Asimismo, resulta llamativo el trazado puntiagudo de la cabeza de la wāw para continuar la línea descendente iniciada por el alify la lām y continuada por la tă. Resulta también curiosa la estrella de ocho puntas que se halla en el centro, con un círculo en el interior.

Se trata de la misma leyenda que aparece en KHAWLI, no 53 (s. XII) y 54 (s. XI/XII), que señala como ilegibles; tienen el mismo estampillado, también con artículo; el primero con una luna creciente $y$ el segundo con una estrella y un motivo floral. En realidad, el $n^{\circ} 53$ está desfigurado, aunque no así el n 54. Es la misma, también, que aparece en DOMÍNGUEZ BEDMAR y ESPINAR MORENO, $n^{\circ} 16$, de la que no ofrecen lectura. En este caso también aparece una estrella de ocho puntas.

60)

$$
\text { at-Tawfía }
$$

A diferencia de la anterior, la waw, también con cabeza puntiaguda, no aparece alineada en diagonal con las letras que le preceden. También aparece con una estrella de ocho puntas, aunque sin círculo en el interior. En realidad, los cuatro extremos de los puntos cardinales no tienen puntas sino que tienen forma cuadrangular.

62) $][[\ldots$

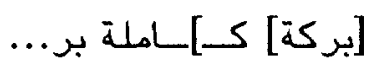

[baraka k] āmila bara...

En esta pieza, de la que se conserva un pequeño fragmento, se repitiría, en escritura cúfica simple, la leyenda baraka kamila.
63)

\section{tawakk.l bi-kum}

En letra cúfica simple. Se trata de la misma que aparece en otras tinajas, como, por ejemplo, en KHAWLI, $n^{\circ}$ 6, quien leyó -creemos que equivocadamente- Al-MulkKamila (sic) y DOMÍNGUEZ BEDMAR y ESPINAR MORENO, $n^{\circ} 5$, quienes no ofrecen ninguna lectura.

El uso de la caligrafía en las cerámicas, con su doble dimensión originaria, comunicativa-simbólica y artística o estética, parece ir estandarizando y fosilizando su valor comunicativo y primando el meramente ornamental, especialmente en contextos populares en los que estaba fuertemente arraigado el analfabetismo. Ello motivaría y explicaría las imitaciones de escritura prácticamente ilegibles que aparecen en ocasiones y que conducen, progresivamente, al surgimiento de seudo-caligrafías, de las que en nuestra muestra encontramos un significativo ejemplo intermedio $\left(n^{\circ} \mid\right)$ y otro avanzado ( $\left.n^{\circ} 4\right)$.

En general, se observa que las incorrecciones y las deficiencias en los trazos de las inscripciones en las cerámicas estudiadas contrastan con la claridad y la corrección que suele caracterizar las inscripciones funerarias almerienses sobre mármol. Ello puede ser debido al grado de profesionalización. Mientras que los epigrafistas habían adquirido una gran profesionalidad, en el caso de la decoración de las cerámicas estas tareas quizás eran realizadas por personas de escasa cualificación en el arte de la caligrafía, en particular en aquellos casos en los que se trataba de piezas que serían adquiridas por los sectores de población con recursos económicos limitados. Algunas de las inscripciones estudiadas, en particular la $n^{\circ} 10$, parecen haber sido realizadas por personas analfabetas. En este sentido, resulta altamente revelador la gran variedad de formas que presenta una misma palabra en una misma vasija, como se puede comprobar en los $n^{\circ} \mid$ y 10 .

Aunque las características epigráficas no resultan determinantes, las piezas podrían datar de la primera mitad del siglo XII y ello, en concreto, porque tanto la unión lām-alif de las $n^{\circ}$ I, 
7 y 14, como la curvatura de la kā $\mathrm{a}$ de la no 20 se asemejan a las de algunas inscripciones funerarias almerienses de esa época. También, la forma de la nūn final de la palabra al-yumn en la $n^{\circ} 3$ se documenta particularmente a partir de la primera mitad del s. XII. Asimismo, la figura de la qāf final de las estampillas $n^{\circ} 59$ y 60 es muy semejante a la que aparece en inscripciones del $5 / 6 / 1122$ y $527 / 1133$. Sobre una de las trazas más curiosas, la y $\vec{a}$ medial en at-tawfíq, nada hemos podido encontrar.

Bien es cierto que, según señaló $M$. Ocaña, fue en la época almohade cuando alternó el cúfico y el nasjī o cursivo, como se produce en algunas de las piezas de nuestro estudio; pero no podemos ignorar que los excelentes estudios epigráficos realizados por Ocaña están referidos a inscripciones realizadas en mármol o en piedra y no en cerámica, como es el caso. En este sentido, creemos que falta mucho por investigar.

\section{CONCLUSIONES}

Somos conscientes, ante todo, de que el material aquí estudiado no fue recogido con metodología arqueológica y sólo contamos con la información proporcionada por quienes presenciaron la destrucción de los alfares. A partir de ello, de los datos proporcionados por excavaciones realizadas en la misma zona y el apoyo de los hechos históricos, hemos realizado este estudio.

Queremos hacer hincapié en que las piezas estaban completas y dentro de los propios hornos y que su fragmentación se debe a la propia pala excavadora. Sólo los restos de tinajas estampilladas se recogieron de forma aislada y en varios puntos del solar.

El lugar donde se produjo el hallazgo ha sido un espacio donde se instalaron alfares desde época califal, anteriores por tanto a su utilización como espacio funerario, tal y como se ha registrado en el Nivel I de la calle Cámaras (MARTINEZ et alii, 1995, p. 99), hasta cristiana. En los niveles superficiales de todas las actuaciones arqueológicas realizadas en la zona se evidencia la presencia de elementos de horno (trébedes y rollos), algunos adheridos en ocasiones a las piezas cerámicas, tratándose de un paquete de desecho. La documentación de este paquete de material, en un área conocida como la de los "alfareros" u "olleros", nos muestra la perduración de los talleres cristianos en el mismo ámbito espacial que ocuparon los talleres hispanomusulmanes (MARTINEZ et alii. 1995, pp.83-I I 6).

La ubicación de los alfares está regulada en el mundo hispano-musulmán mediante tratados de hisba (Ibn 'Abdūn) disponiéndose que los alfareros estén extramuros.

Aquí, por lo tanto, se produce una asociación espacial entre actividad alfarera y necrópolis, como sucede en Murcia (NAVARRO PALAZON. 1990), Bezmiliana (ACIÉN, 1990) y Toledo (MARTINEZ LILLO, 1990). Los alfares son coetáneos a los primeros enterramientos de este espacio extramuros de Puerta de Pechina (Bāb Baŷȳàna), e idéntico material aparece formando parte de algunas estructuras de las tumbas. Así se confirma en la excavación Avda de Pablo Iglesias I y II, cuyo material cerámico asociado al nivel de las tumbas se fechó fundamentalmente en el siglo XII (MARTINEZ et alii, 1995, pp.95-96).

Posteriormente, en época almohade y nazarí, el espacio industrial es abandonado e invadido por las sepulturas a raíz de la ampliación del cementerio tal y como se constata en este solar y en la próxima Plaza de los Derechos Humanos (MARTINEZ et alii, 1995, p.I0I). A partir de entonces, la producción es ya limitada teniendo como base el consumo interno. Ello supone un desplazamiento de los alfares al norte del área, pero próximos a las zonas funerarias, ya que en el nivel superficial de las tumbas, siempre han aparecido restos de testares cristianos, posiblemente debido a los arrastres de la Rambla de Alfareros.

En los alfares existió una especialización en las producciones, ya que se han constatado "hornadas" de piezas similares: cántaros (en el alfar de la Terraza Imperial, ya mencionados), o jarritas en manganeso- esgrafiado, como en este caso. 
Técnicamente ya hemos mencionado el torneado perfecto; se trata de vasos muy finos (esgrafiado), aunque en la pasta se aprecian intrusiones calizas que estallaron durante la cochura.

En el caso de los ejemplares decorados con técnica de cuerda seca, mientras que la ejecución es buena (caso de las jarritas de cuerda seca parcial), la decoración es muy descuidada, desbordando el vidriado el trazo de manganeso, o estando aquel en numerosas ocasiones rehervido.

Se han constatado como técnicas decorativas las producidas mediante la aplicación de vidriados coloreados, concretamente un melado amarillo que acompaña a las redomas y peana del candil de pie alto y un verde turquesa dispuesto en el interior del jarro con pico vertedor, tapaderas y taza; manganeso- esgrafiado, cuerda seca total y parcial, pintada a la almagra, estampillada, incisa, excisa, a molde y apliques plásticos.

Hemos constatado la presencia de formas idénticas con o sin decoración; tal es el caso de las jarras de cuerda seca o del plato estampillado. ¿Se trata, en el primer caso, de piezas destinadas a comercializarse como tales? o bien ise plantean dos cochuras para la cuerda seca parcial?. En el segundo caso es evidente que se realizó la estampilla sobre el barro fresco y se procedió a su cocción. Después se aplicaría el vidriado pues, lógicamente, sin vidriar se invalida su función.

Igualmente ocurre con la presencia del fragmento esgrafiado carente de manganeso, por otro lado con idéntica decoración que las jarrita $n^{\circ} 5$ de la Fig.3

¿Puede tratarse de pruebas o fallos en la producción?

Sobre la fabricación de las piezas en este lugar no hay ninguna duda. Abundan los útiles de alfarero hartamente conocidos como son las trébedes, pero constatamos otros nuevos como las lengüetas o ¿bases para levantar las jarras? (Lám. I, II, III, IV). Respecto a esto último hemos com- probado que dicho elemento encaja perfectamente en el tipo B sin decorar.

Esta riqueza, variedad y gran producción creemos que debe corresponder con el momento de máximo esplendor y desarrollo económico almeriense.

Pensamos en la posibilidad de que la producción tuviese como objetivo no el exclusivo abastecimiento interno, sino el mercado exterior, lo que nos lleva a considerar Almería como un centro industrial cuyos productos exportados podían rastrearse en lugares peninsulares e insulares (relaciones de nuestro material con el de Denia, Caños de Meca (Barbate), Zavellá y Mértola). También en el Norte de Africa (Ceuta y Lixus).

Para la datación de todo el conjunto hemos tenido en cuenta, tanto la epigrafía que aparece en las vasijas y su semejanza con la de las lápidas funerarias de la primera mitad del siglo XII publicadas por Ocaña, como la comparación con la primera loza dorada de al-Andalus que sabemos se fabricó en Almería. También con las estructuras funerarias excavadas en la necrópolis de Bāb Baŷyāna en las que fragmentos de vasijas similares a los que hemos presentado, y decoradas con las mismas técnicas, formaban parte de la construcción.

Todo ello nos permite fechar estas producciones en el siglo XIl.

Ahora bien, el hecho de haber aparecido los hornos abandonados con las piezas dentro y ser vasijas de una alta calidad, tanto técnica como decorativa y, por tanto, de gran valor económico, nos plantea un interrogante: ¿Qué circunstancia social o politica pudo provocar el abandono, de manera precipitada de tantos hornos y, por consiguiente, de tan alta pérdida económica?

Descartando el intento de invasión por Jaime II (Siglo XIV), y la Peste Negra que asoló la ciudad (siglo XIV), y que no conocemos ninguna circunstancia lo suficientemente significativa en el siglo XIII, sólo nos queda por ahora, que el único hecho que pudo provocar tal situa- 
ción de abandono fue la situación que se vivió durante el asedio y conquista de la ciudad a manos de Alfonso VII y sus aliados en I I 47, Io que acarreó la ruina de Almería tal y como manifiestan los textos árabes. Los diez años de la permanencia cristiana en la ciudad trajeron como consecuencia la pérdida de su preponderancia económica y una sangría humana de la que nunca se recuperó, constatada arqueológicamente.

¿Podría esta fecha servir de límite a estas producciones? Sólo futuras investigaciones en el área almeriense podrán precisar con detalle la datación.

\section{FUENTES ÁRABES}

AL-IDRT̄Sī, Abū 'Abd Allah Muḥammad (4937/I I 00- 560/ I I 64/5), Nuzhat al-muštāq, ed. Ė Cerulli, F. Gabrieli, G. Levi Della Vida y otros. Opus Geographicum, 9 fascículos, Nápoles, 1970-75.

AL-MAQQARĪ, Šihāb al-Dīn Abū l- 'Abbās Aḥmad b. Muḥammad al-Tilimsānī (m. I045/l63I), Nafh al-țīb, ed. Iḥā̃n 'Abbās, 8 vols., Beirut, 1968.

AL-RUŠĀṬī, Abū Muḥammad (466// 074-542/ | |47), Kitāb lqtibās al-anwār, ed. parcial. E. Molina López y J. Bosch Vilá, al-Andalus en el Kitāb iqtibās al-anwār y en el ljtišār iqtibās al-anwār, Madrid: CSIC-IHAC, 1990.

AL-'UDRT̄, Abū l-'Abbās Aḥmad (393/l 003-478/l085), Taršĩ al-ajbār, ed. 'Abd al-'Azīz al-Ahwānī, Nusūs 'ani lAndalus min kitāb Tarși 'al-ajbār wa-tanwì al-ātār wa-l-bustān fĩ garāilib al-buldān wa-l-masālik ilà ŷamī al-mamālik, Madrid: IEEI, 1965.

\section{BIBLIOGRAFÍA}

ACIÉN ALMANSA, M. (1990): "Homos alfareros de época califal en el yacimiento de Bezmiliana". Fours de potiers et "Testares" médiévaux en Méditerranée Occidentale. Madrid, 13-27.

ACIÉN ALMANSA, M.; CASTILLO GALDEANO, F.; FERNANDEZ GUIRADO, M. I.; MARTINEZ MADRID, R.; PERAL BEJARANO, C.; VALLEJO TRIANO, A. (|99|),(1995). "Evolución de los tipos cerámicos en el S.E de Al-Andalus." V Colloque International sur la céramique médiévale en Méditerranée Occidentale. Rabat, 1991, 125139.
ATAALLAH, M. (1967):"La ceramique musulmane a paroi fine incisee ou peinte de Lixus". Bulletin d'Archéologie Marrocaine, 7, 627-639.

AZUAR RUIZ, R. (1986): "Apunte para un ensayo de evolución crono-tipológica de la redoma hispanomusulmana". Segundo Coloquio Internacional de Cerámica medieval en el Mediterráneo Occidental. Toledo, 1981. Madrid, |85-19|.

AZUAR RUIZ, R. (1989): Denia islámica. Arqueología y poblamiento. Alicante.

BARCELÓ, C. (1990): "La epigrafía ornamental". J. V. Lerma y otros. Cerámica islámica en la ciudad de Valencia. Valencia, II, |37-|4|.

CAVILLA SÁNCHEZ-MOLERO, F. (1992): "La cerámica hispano-musulmana de Beca". Los caños de Meca. Barbate. Cádiz.

COLL CONESA, J; MARTI OLTRA, j; PASCUAL PACHECO, J. (1988): Cerámica y cambio cultural. El tránsito de la Valencia islámica a la cristiana. Valencia.

DOMINGUEZ BEDMAR, M. y ESPINAR MORENO, M. (1987): "Catalogación preliminar de estampillas almerienses", Actas do IV Congresso de Cerâmica Medieval do Mediterrâneo Ocidental, Lisboa, 593-599.

DUDA,D. (1970): Spanisch Islamische Keramik aus Almeria. Vom 12. bis 15. Jahrundert, Heidelberg.

EGEA GONZÁLEZ, J. J; CANTERO SOSA, M; POZO MARÍN, R. (En prensa): "Informe de la intervención arqueológica de emergencia en el solar calle Marín". Almería. 1992. Anuario Arqueológico de Andalucía.

FERNÁNDEZ SOTELO, E. (1988): Ceuta medieval. Aportación al estudio de las cerámicas (Siglos X-XV). Vol. I-III, Ceuta.

FLORES ESCOBOSA, I; MUÑOZ MARTÍN, M.M.; MARINETTO SÁNCHEZ, P. (1993): "Vivir en Al-Andalus". Exposición de cerámica. S. IX-XV. Almería.

FLORES ESCOBOSA, I y MUÑOZ MARTIN M․ Mar. (1995): "Cerámica nazarí (Almería, Granada y Málaga). Siglos XIII-XV." Spanish Medieval Ceramics in Spain and the British Isles. Oxford.

FLORES ESCOBOSA, I.; MUÑOZ MARTÍN Ma. M. y DOMINGUEZ BEDMAR, M. (1989): Cerámica Hispanomusulmana en Almería: Loza dorada y azul. Almería.

FLURY, S., (1924): "Une formule épigraphique de la cerámica archaïque del Islam", Siria, V, 53-66.

GARCÍA LÓPEZ, J.L; CARA BARRIONUEVO, L; FLORES ESCOBOSA, I; ORTÍZ SOLER, D.(1990): "Urbanismo en rabad al-Musalla de Almería. Excavaciones en C/Álvarez de Castro". Anuario Arqueológico de Andalucía III, Actividades de urgencia, 7-17. 
GARCÍA LÓPEZ, J. L.CARA BARRIONUEVO, L. (1992): "Delimitación del área de interés arqueológico. Propuesta de zonificación arqueológica del suelo urbano incluido en el conjunto histórico de la ciudad de Almería". Anuario Arqueológico de Andalucia III. Actividades de urgencia. Sevilla, 30-35.

GARCÍA LÓPEZ, J. L;; CARA BARRIONUEVO, L; FLORES ESCOBOSA, I; MORALES SÁNCHEZ, R. (1992): "La organización de espacios públicos y ámbitos privados en la Almería de los siglos XI y XII. Excavaciones en la calle Mariana". Anuario Arqueológico de Andalucia III. Actividades de urgencia. Sevilla, I3-29.

GISBERT SANTONJA, J. A.; BURGUERA SAN MATEU, V; BOLUFER i MARQUES, J. (1992): La cerámica de DaniyaDenia, alfares y ajuares domésticos de los siglos XII-XIII. Valencia.

KWALI, Abdallah, (1992): "Lote de cerâmica epigrafada em estampilhagem de Mértola", Arqueologia Medieval. Campo Arqueológico de Mértola, 7-25.

LIROLA DELGADO, J. (1992): "Los nombres árabes de las puertas de la ciudad de Almería". Homenaje a la profesora Elena Pezzi. Granada, 39-54.

LOPEZ DE COCA Y CASTAÑER, J. E. (1980): "Los reinos de Taifas y las dinastías bereberes". Historia de Andalucia II. Madrid, 13-94.

MOLINA LÓPEZ, E. (1986): "Almería islámica "Puerta de Oriente" objetivo militar (nuevos datos para su estudio en el "Kitab lqtibās al-anwār" de al-Rušāțī". Actas del XII Congreso de la U.E.A (Málaga 1984). M, 559-608.

MOLINA LÓPEZ, E. (1990): "Almería en el etapa Nasri" (siglos XIII-XV). Estado de la Cuestión,balance y perspectiva". Coloquio Almería entre culturas (Siglos XIII-XVI). Tomo I. I.E.A, I5-65.

MARINETTO SÁNCHEZ, P. y FLORES ESCOBOSA, I. (1995): "Estudio tipo-cronológico de la cerámica nazarí. Elementos de agua y fuego". V Colloque sur la cerámique médiévale en Méditerránee Occidentale. Rabat, (|99|), I78190.

MARTINEZ GARCÍA J; MELLADO SÁEZ, C; MUÑOZ MARTÍN, M. M. (1995): "Las necrópolis hispanomusulmanas de Almería". Estudios sobre cementerios islámicos andalusíes. Málaga, 83- I I I.

MARTÍNEZ LILLO, S. (1990): "Hornos califales de Toledo". Fours de potiers et "Testares" médiévaux en Méditerranée occidentale. Madrid, 45-6I.

MUNZER, J. (1987): Viaje por España y Portugal. Granada.
NAVARRO PALAZÓN, J.(1987): " Nuevas aportaciones al estudio de la loza dorada andalusí: el ataifor de Zavella". Les Illes Orientals D 'Al-Andalus. V Jornades D'Estudis històrics locals. Palma de Mallorca, 225-238.

NAVARRO PALAZÓN,J. (1990): "La cerámica con decoración esgrafiada". En La cerámica islámica en la ciudad de Valencia II. Valencia I 17-I35.

NAVARRO PALAZÓN, J. (1990): "Los materiales islámicos del alfar antiguo de San Nicolás de Murcia". Fours de Potiers et "testares" médiévaux en Méditerranée Occidentale. Madrid, 29-43.

NAVARRO PALAZÓN, j; JIMENEZ CASTILLO, P. (1995): "La producción cerámica medieval de Murcia". Spanish Medieval Ceramics in Spain and the British Isles. Oxford, I85214.

OCAÑA JIMÉNEZ, M. (1988): "Historia y epigrafía en la Almería islámica". I Encuentro de cultura Mediterránea. Almería, 173-188.

OCAÑA JIMÉNEZ, M. (1945): "Zócalos hispanomusulmanes del siglo XII", Al-Andalus, X, I64-169.

OCAÑA JIMÉNEZ, M. (1964): Repertorio de inscripciones árabes de Almería, Madrid-Granada.

OCAÑA JIMÉNEZ, M. (1970): El cúfico hispano y su evolución, Madrid.

OCAÑA JIMÉNEZ, M. (1983): "La epigrafía hispano-árabe durante el periodo de Taifas y Almorávides", Actas del IV Coloquio Hispano-tunecino, Madrid, 197-204.

ROSSELLÓ BORDOY, G. (1978): Ensayo de sistematización de la cerámica árabe en Mallorca. Palma de Mallorca.

ROSSELLÓ PONS, M. (1983): Les ceràmiques almohades del carrer de Zavellá. Ciutat de Mallorca. Palma de Mallorca.

TORRES BALBÁS. L. (1957): "Almería Islámica". al-Andalus, XXII. Madrid-Granada, 4I I-457.

TORRES BALBÁS, L. (1985): Ciudades hispanomusulmanas. Madrid.

TORRES, C. (1987): "Cerâmica islâmica Portuguesa". Catálogo. Mértola.

TORRES, C; PALMA. M. P; REGO, M; MACÍAS, S. (): "Cerâmica islâmica de Mértola- propostas de cronologia e funcionalidade". A Cerâmica medieval no Mediterrâneo ocidental. Lisboa, 1987 (1991), 497-536. 


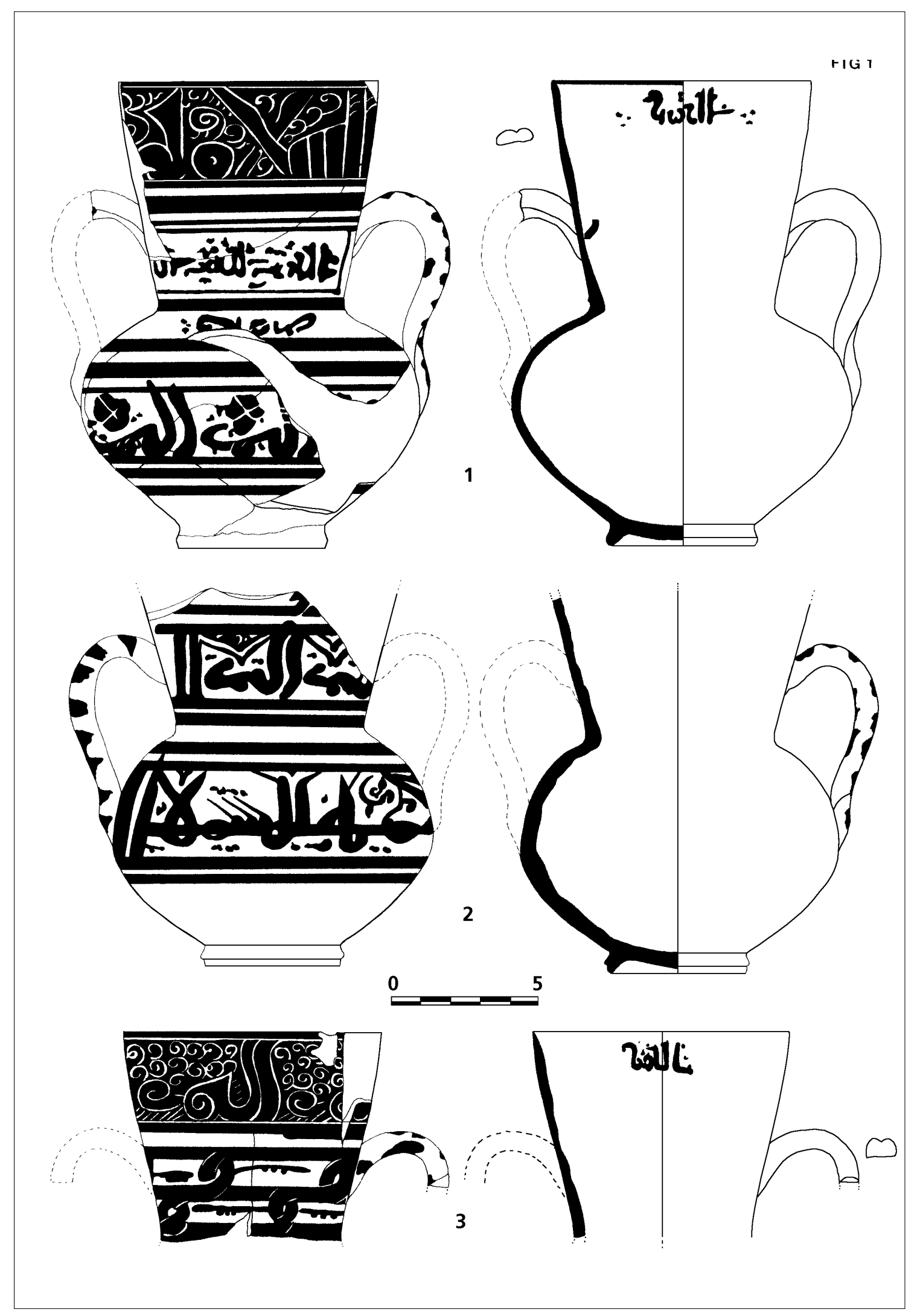

Fig. I 


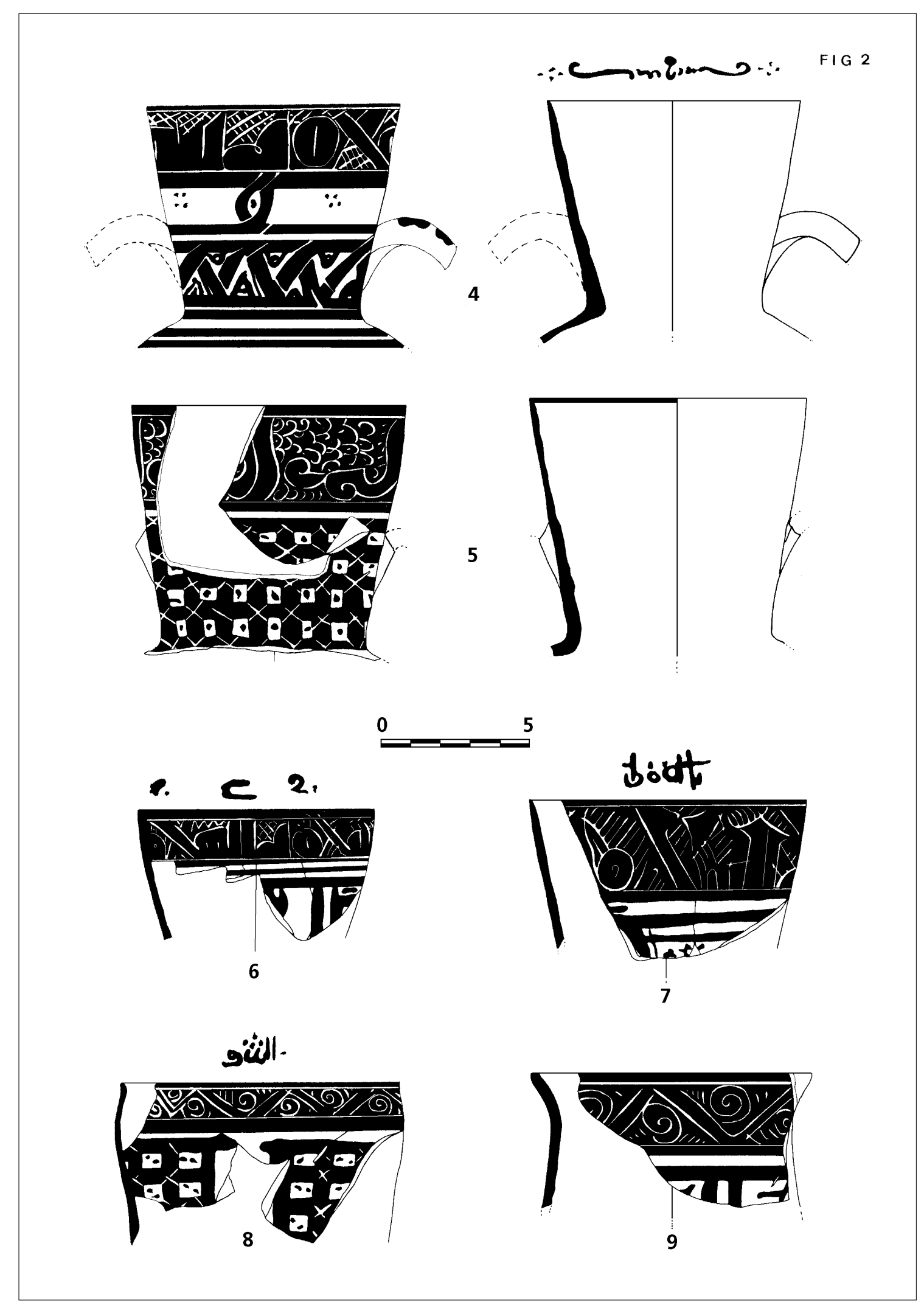

Fig. 2 

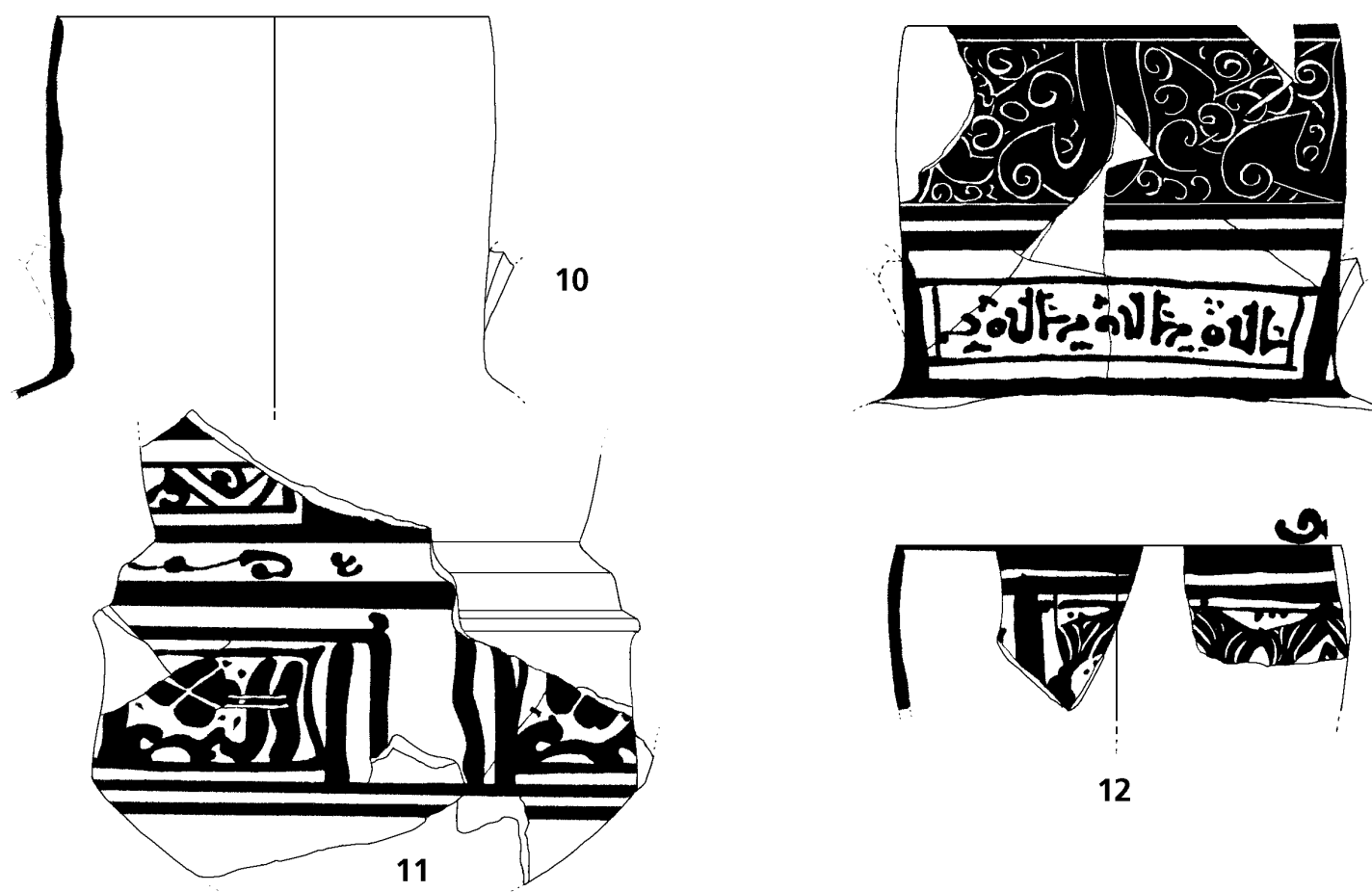

12
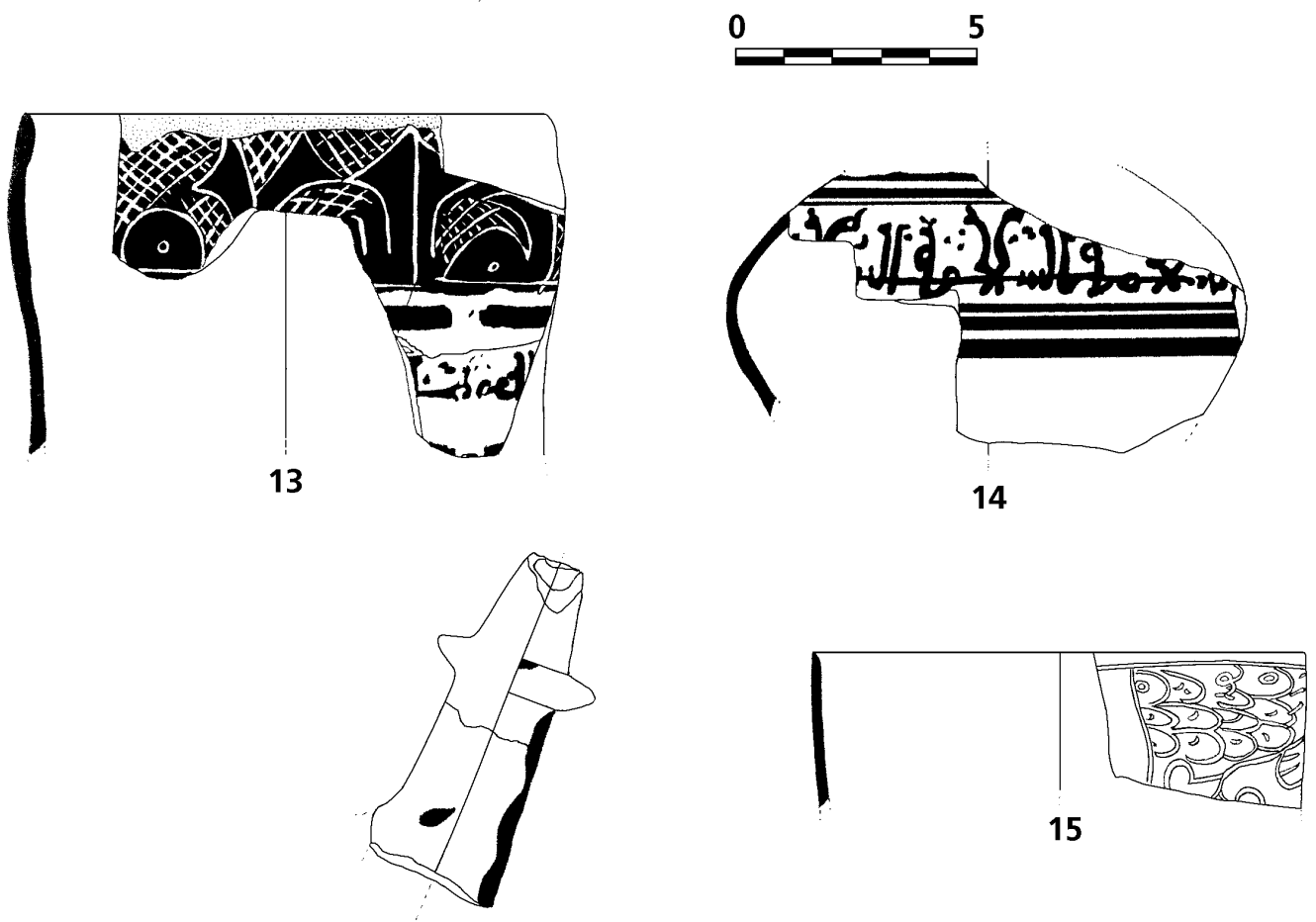

Fig. 3 


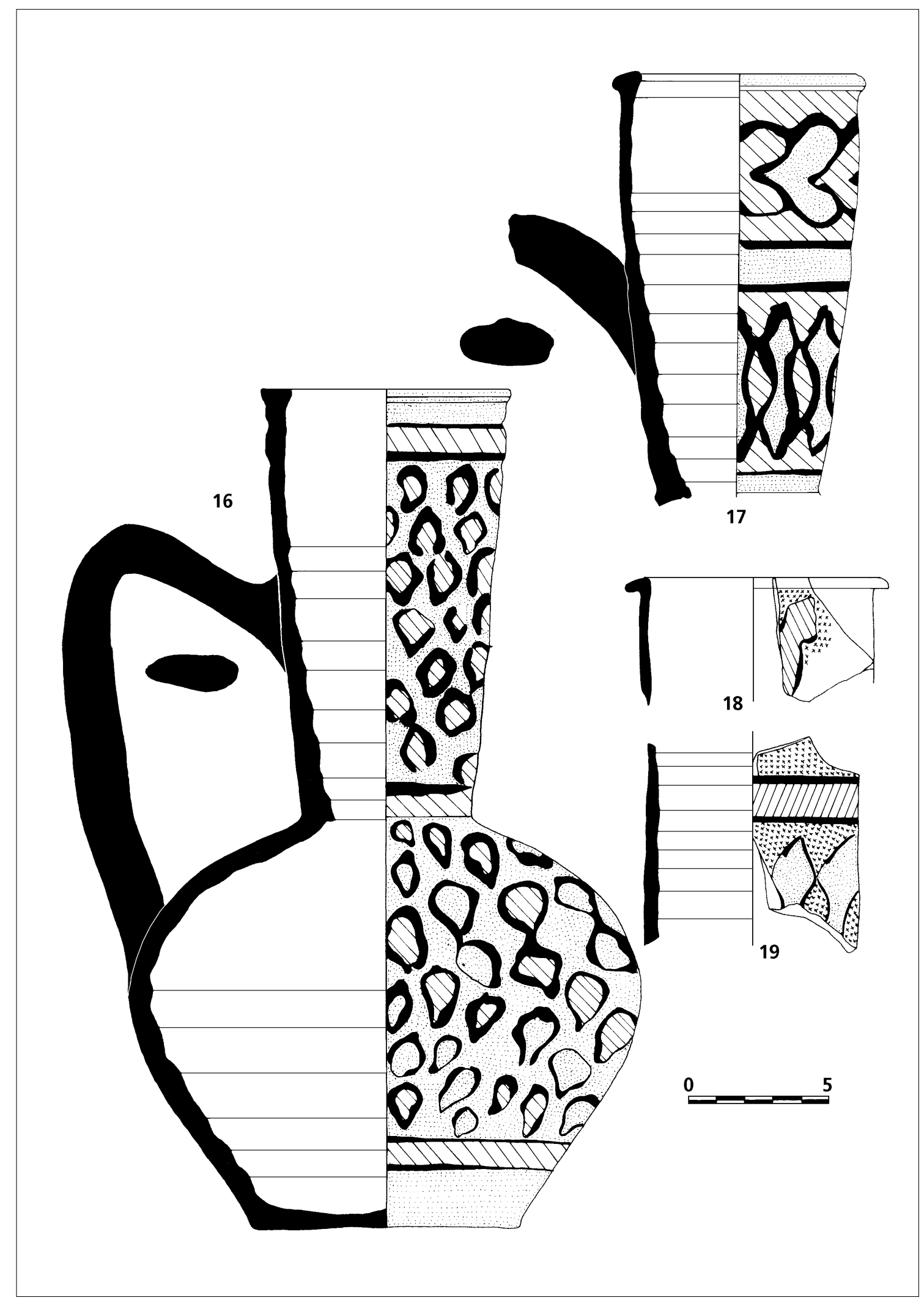

Fig. 4 


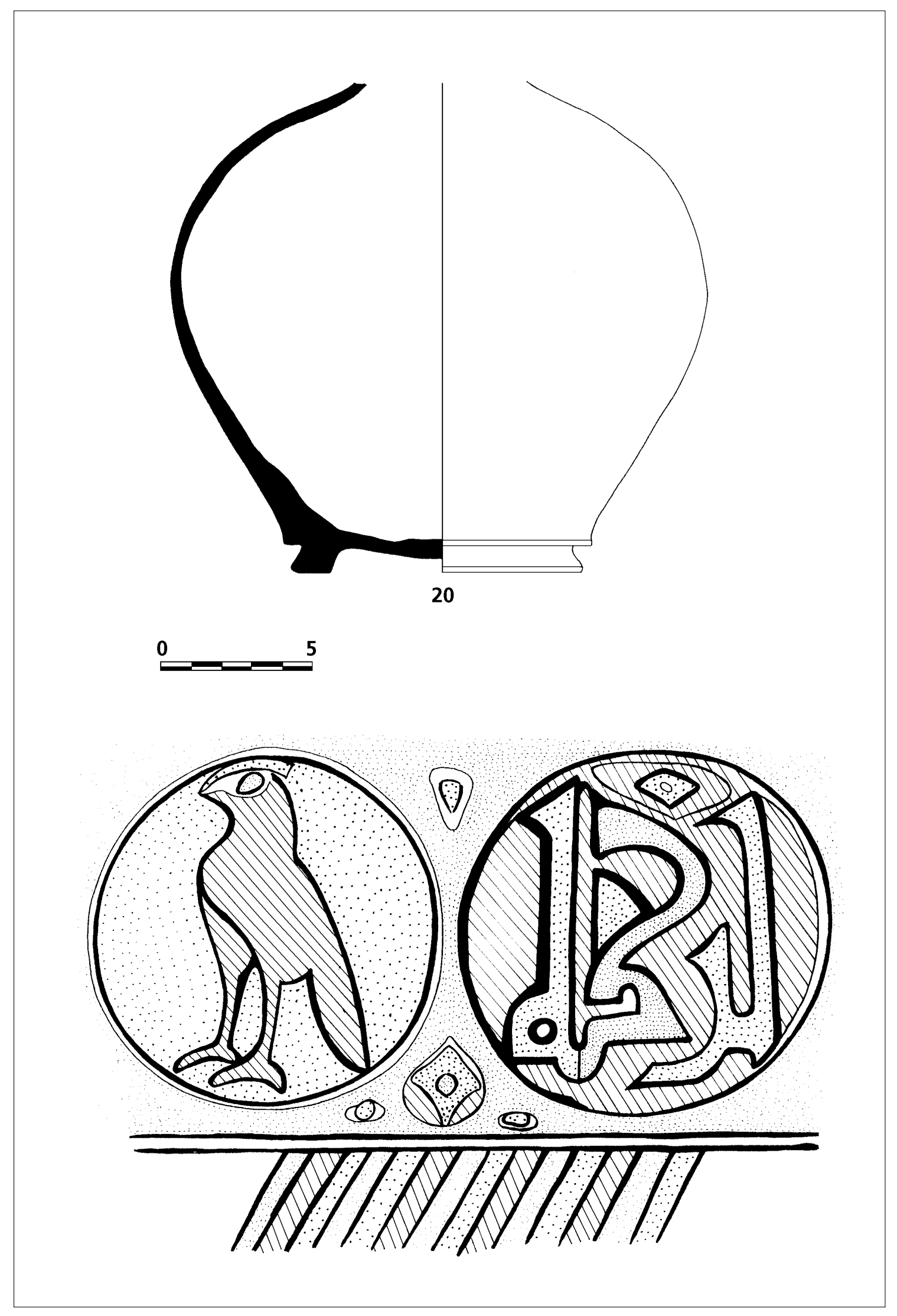

Fig. 5 


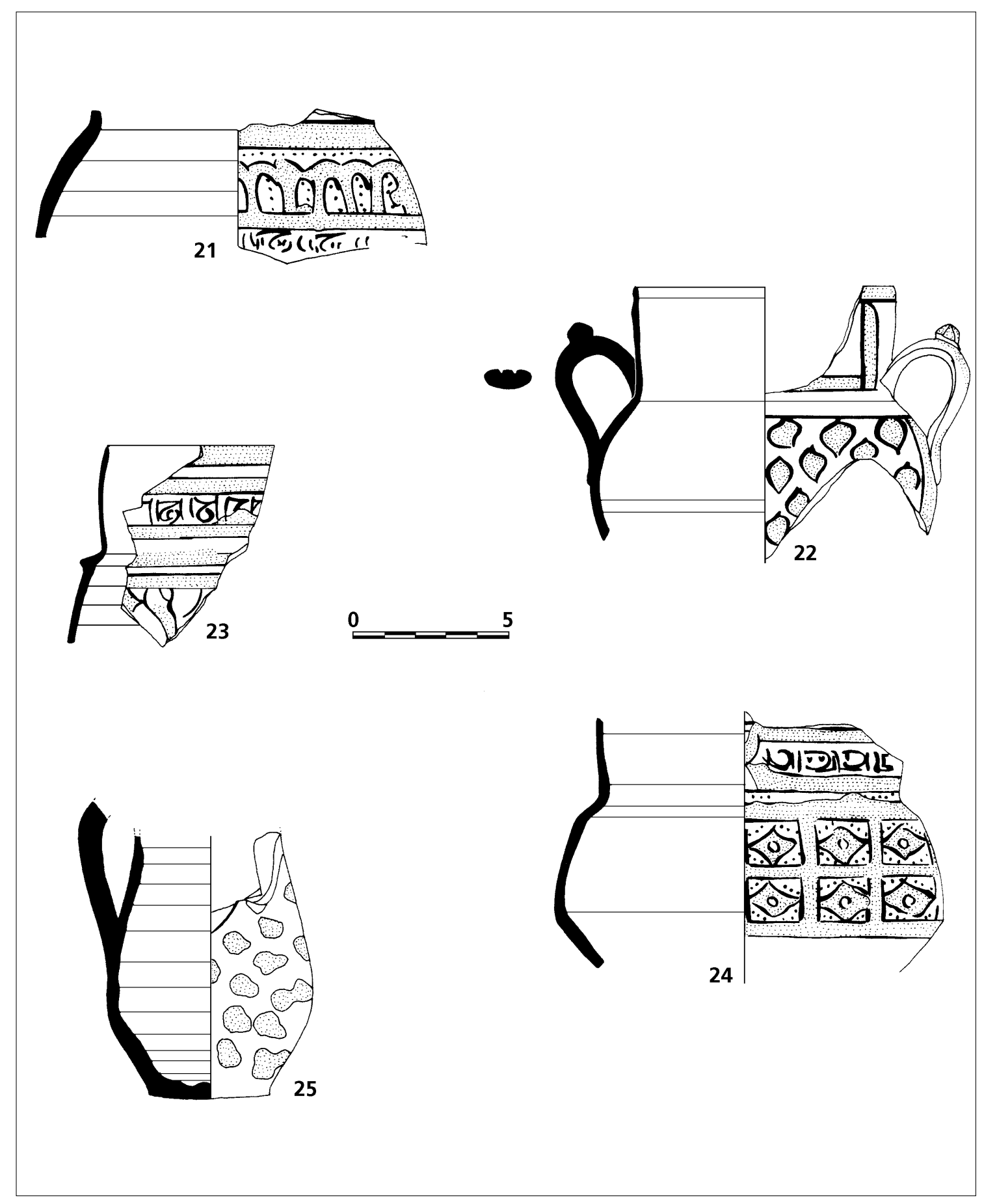

Fig. 6 


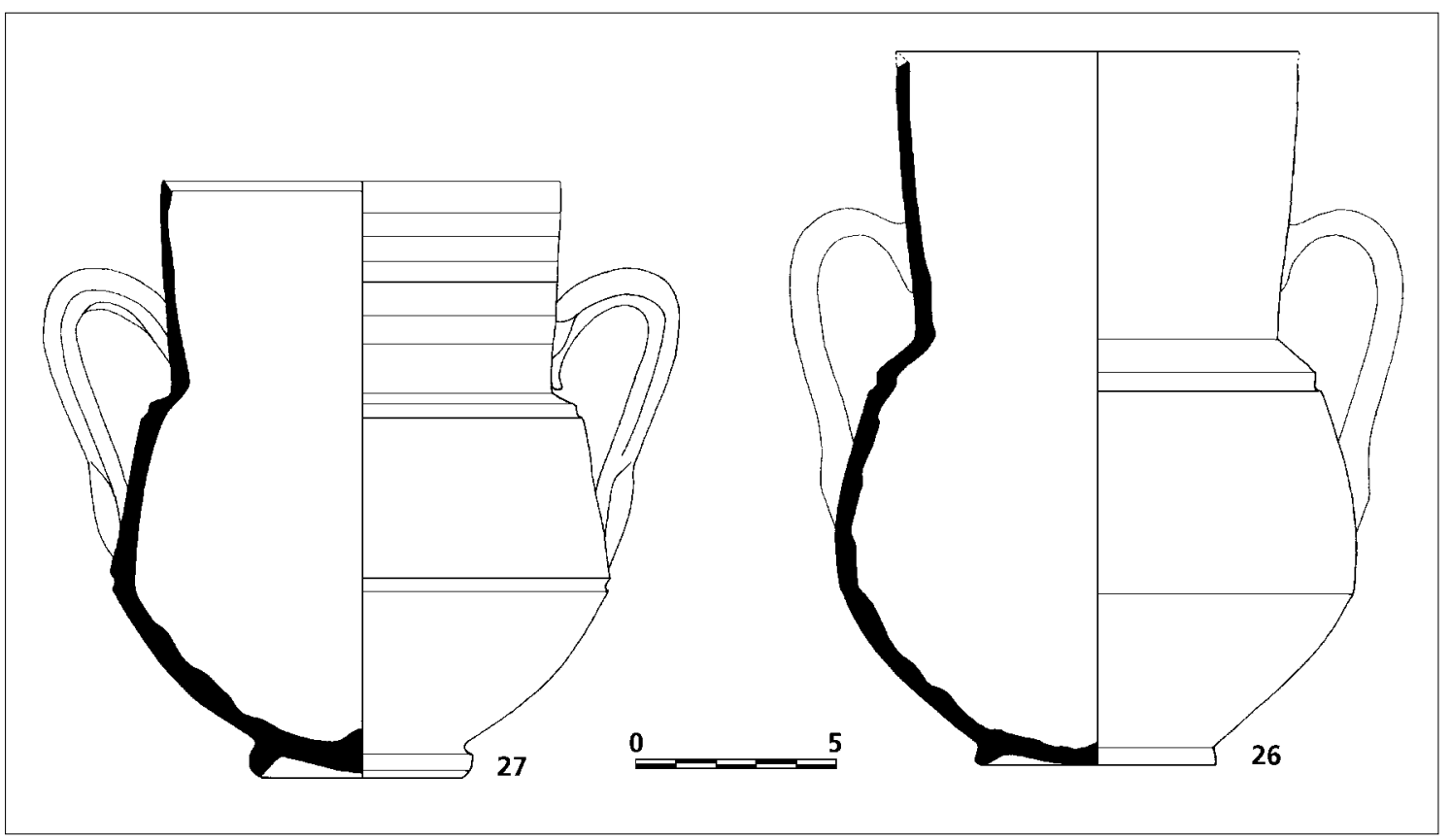

Fig. 7

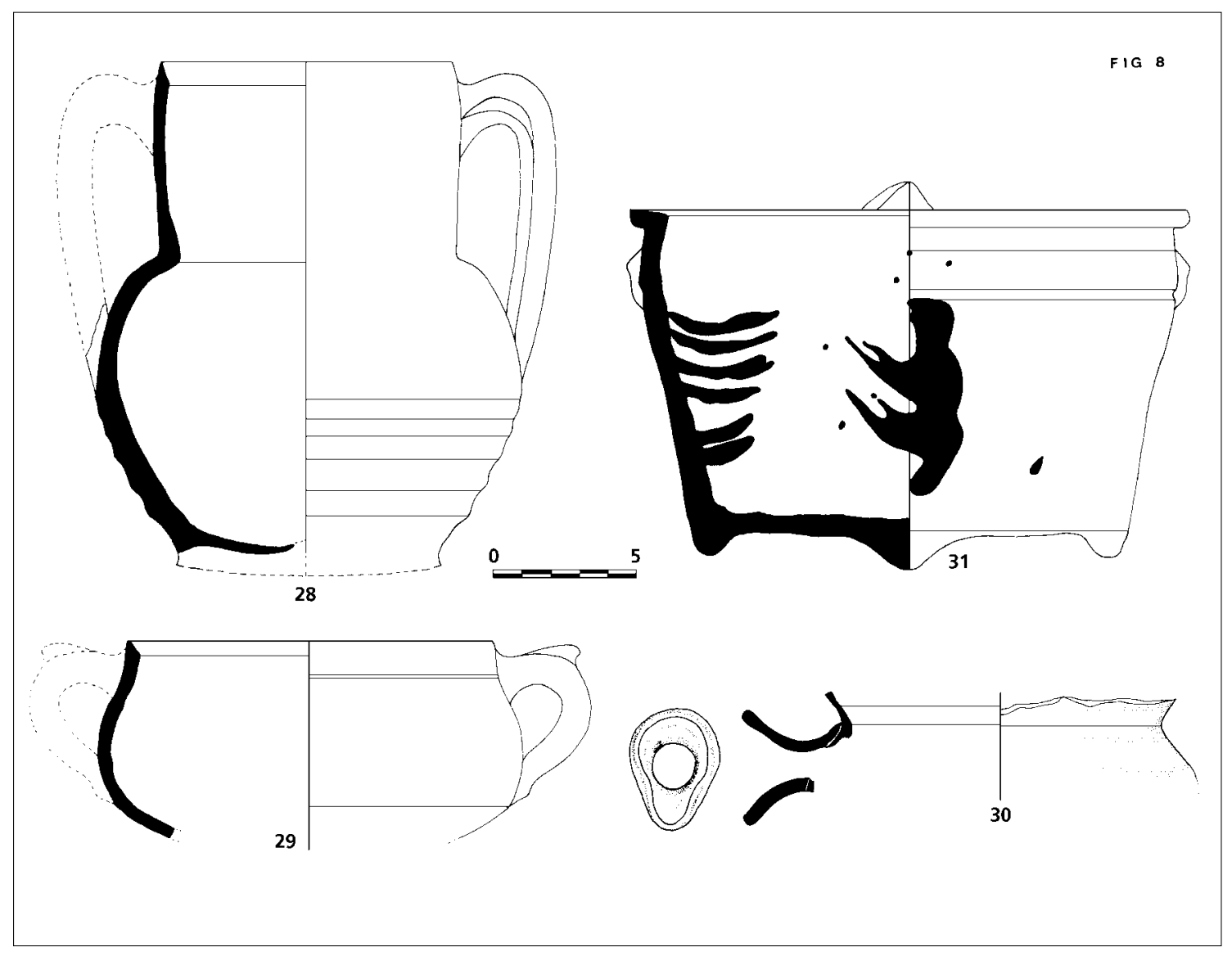

Fig. 8 


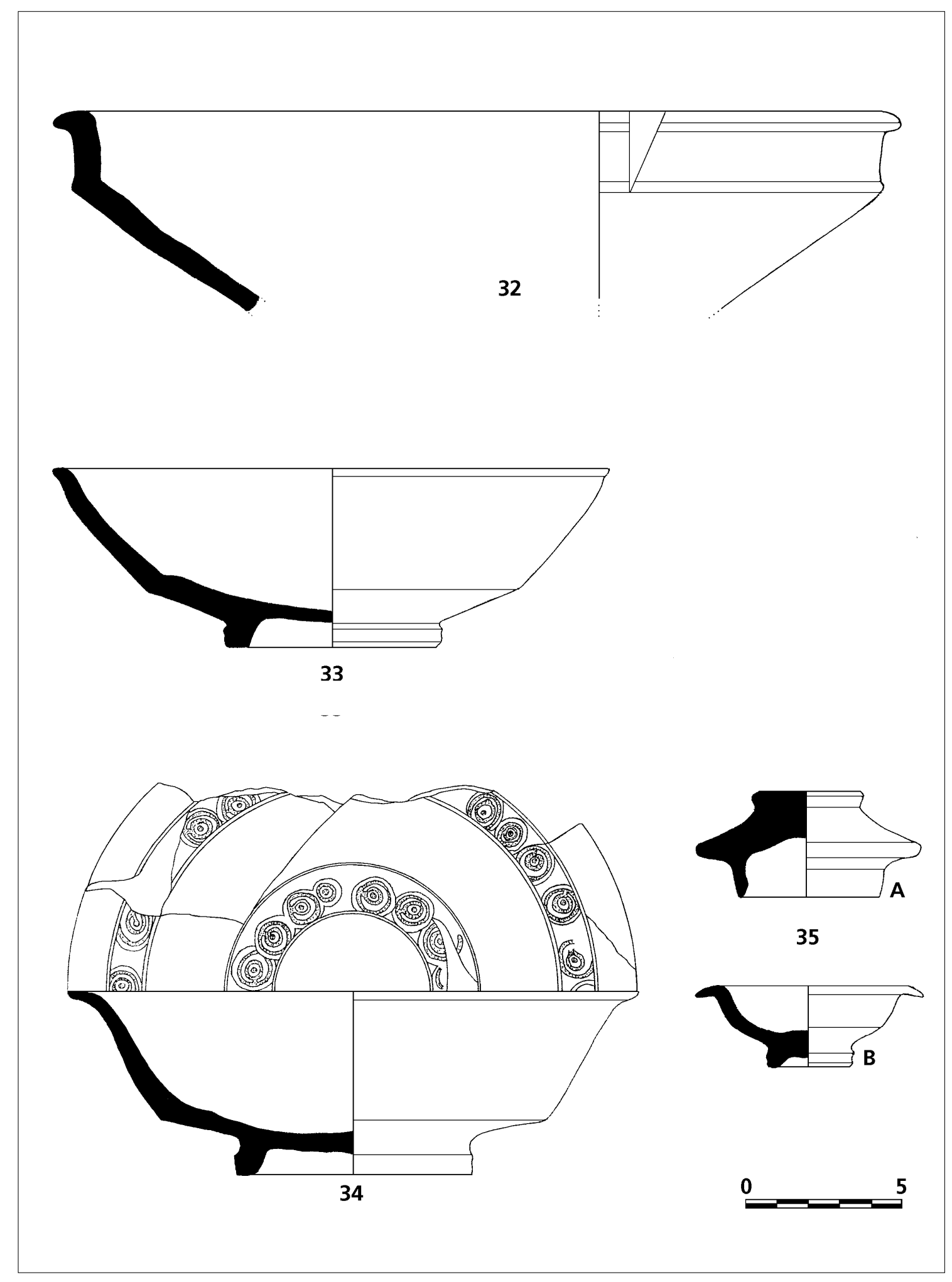

Fig. 9 

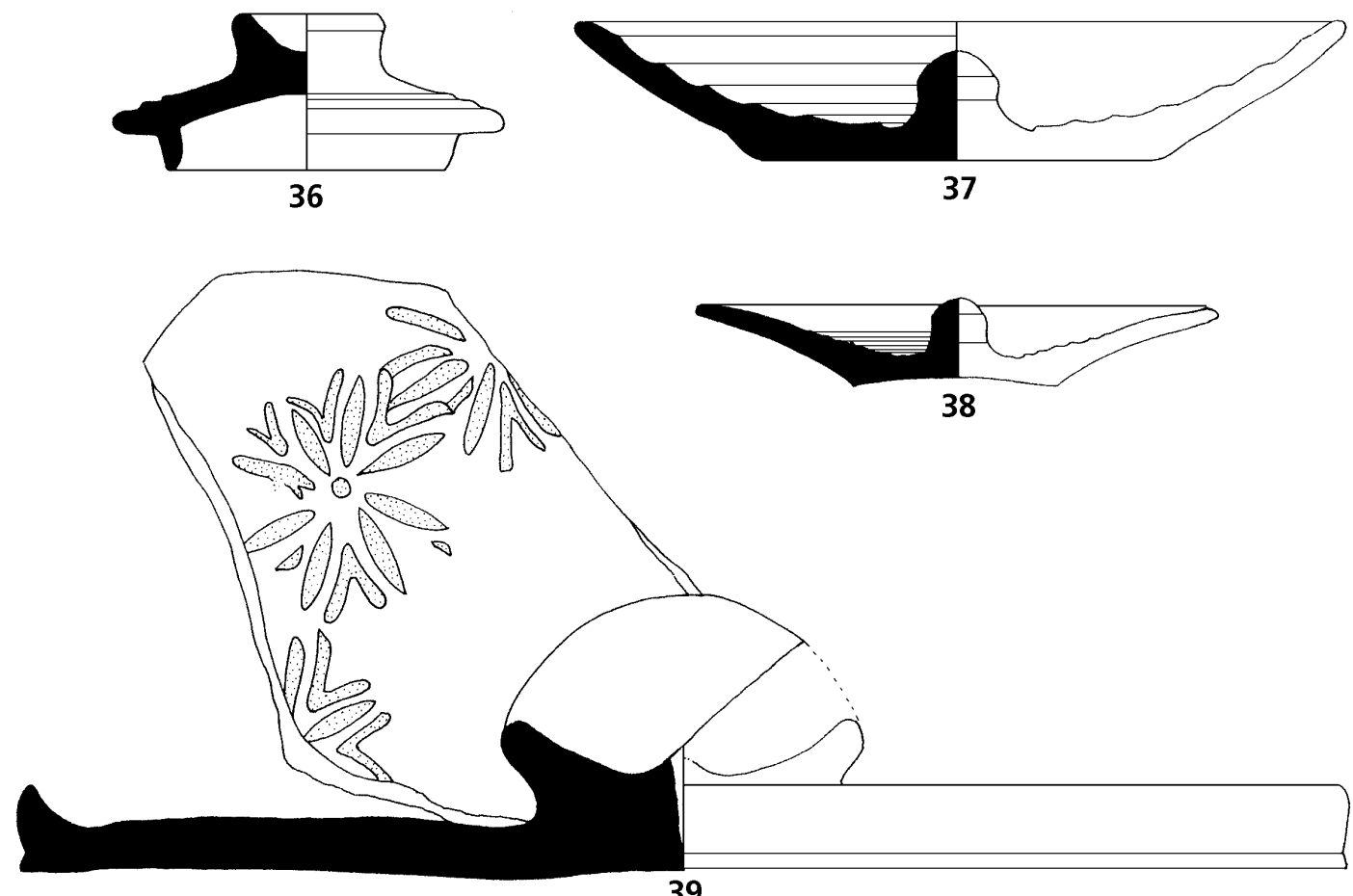

39

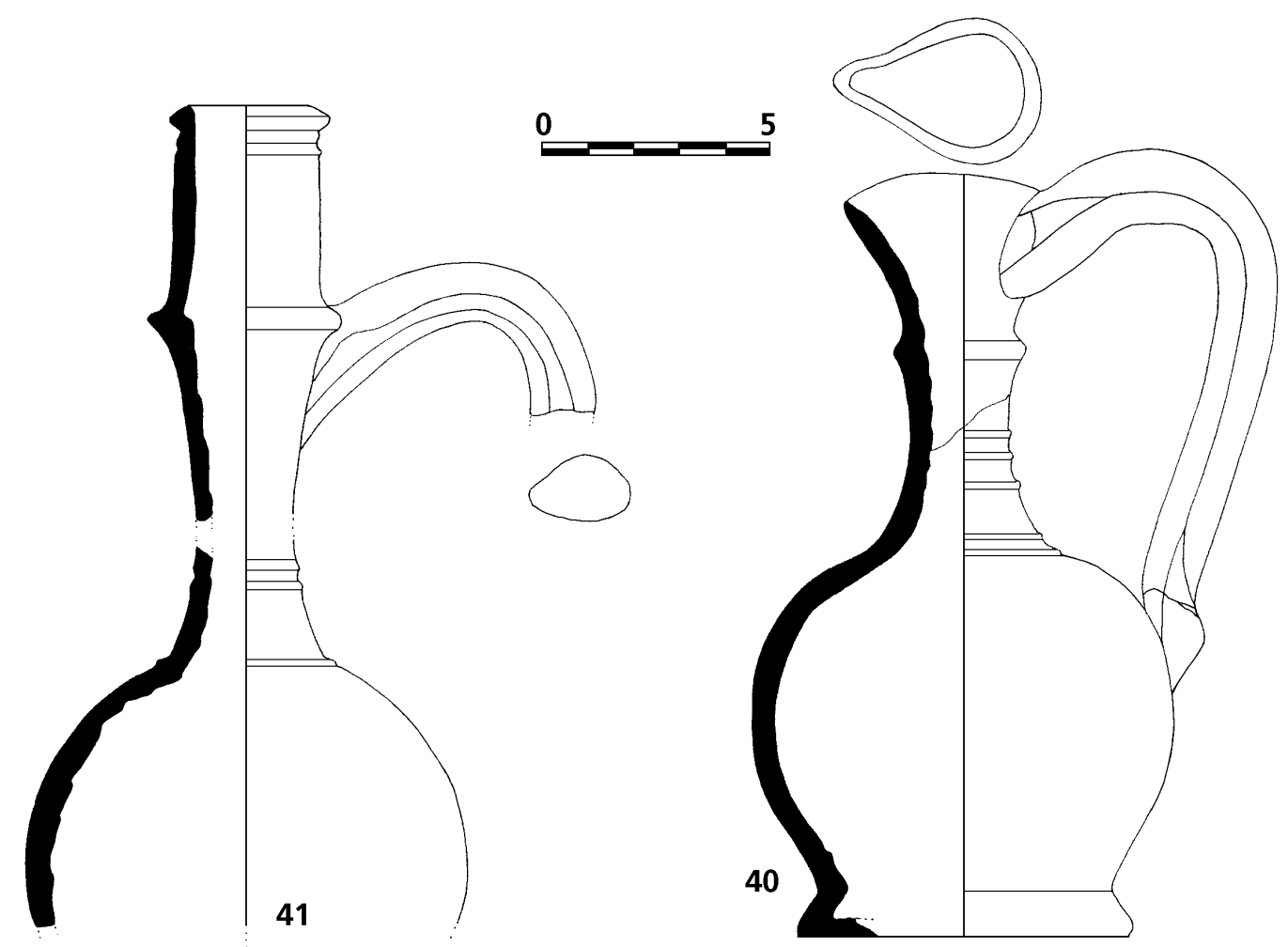

Fig. 10 


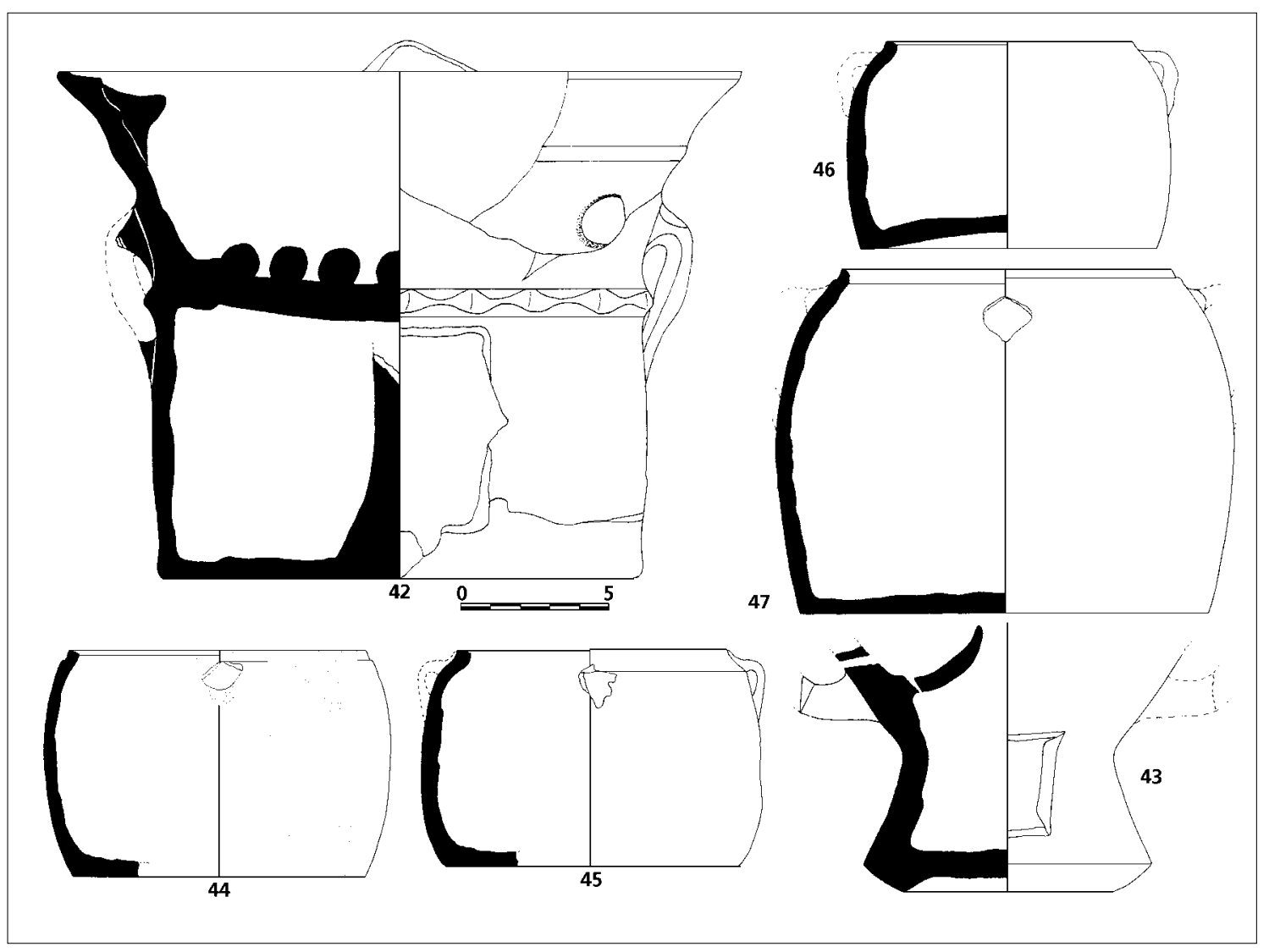

Fig. I I

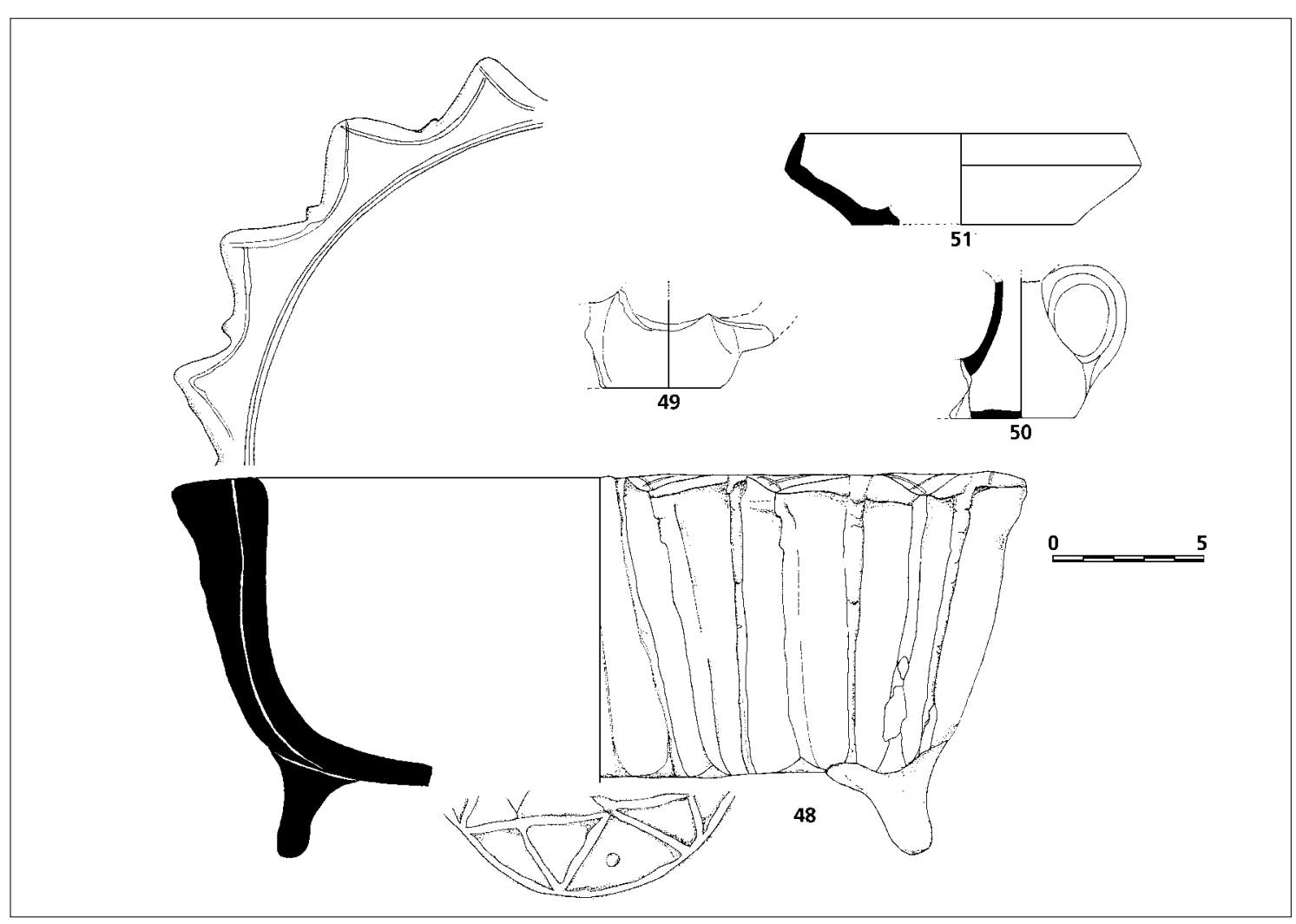

Fig. 12 


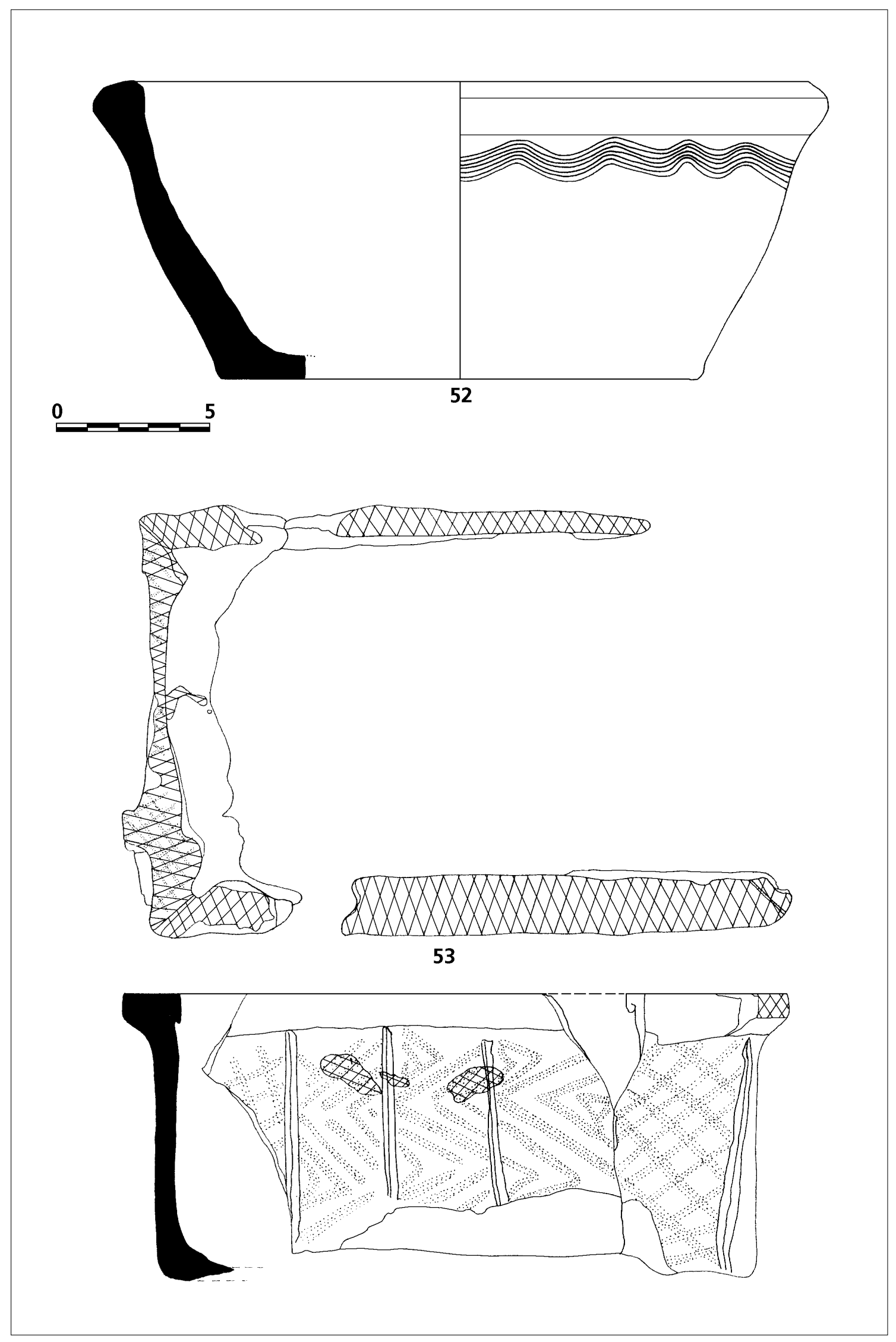

Fig. I 3 


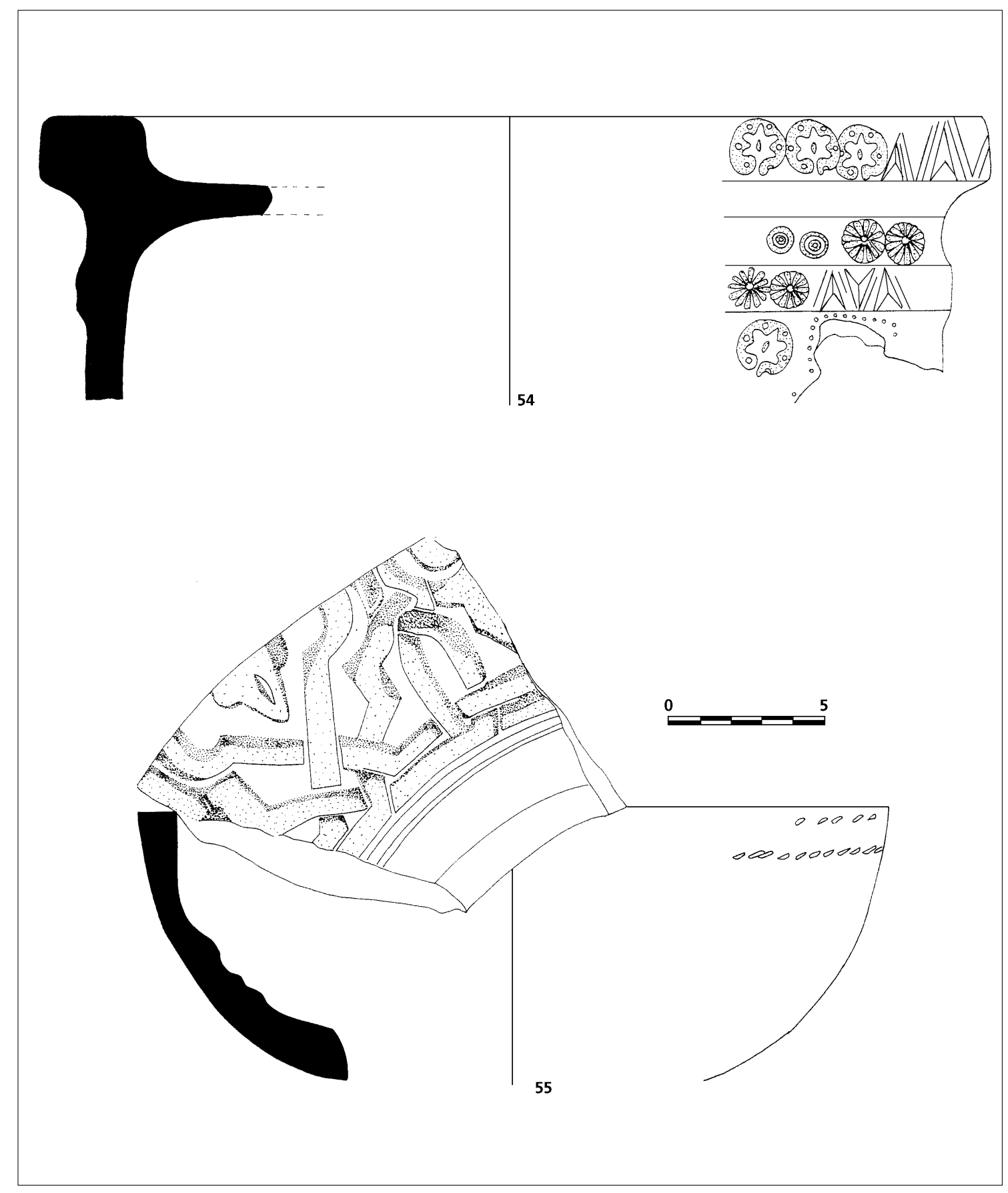

Fig. 14 


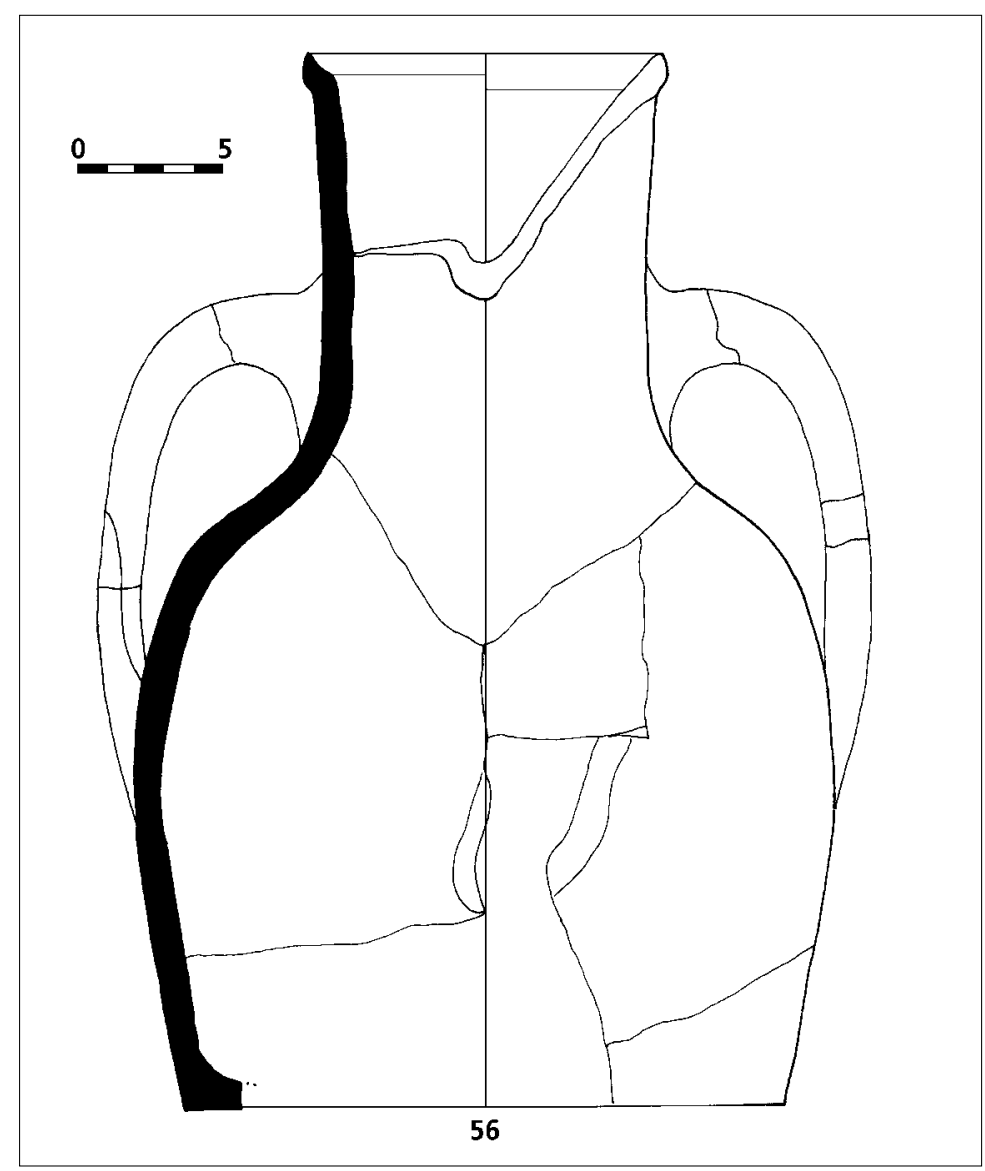

Fig. 15

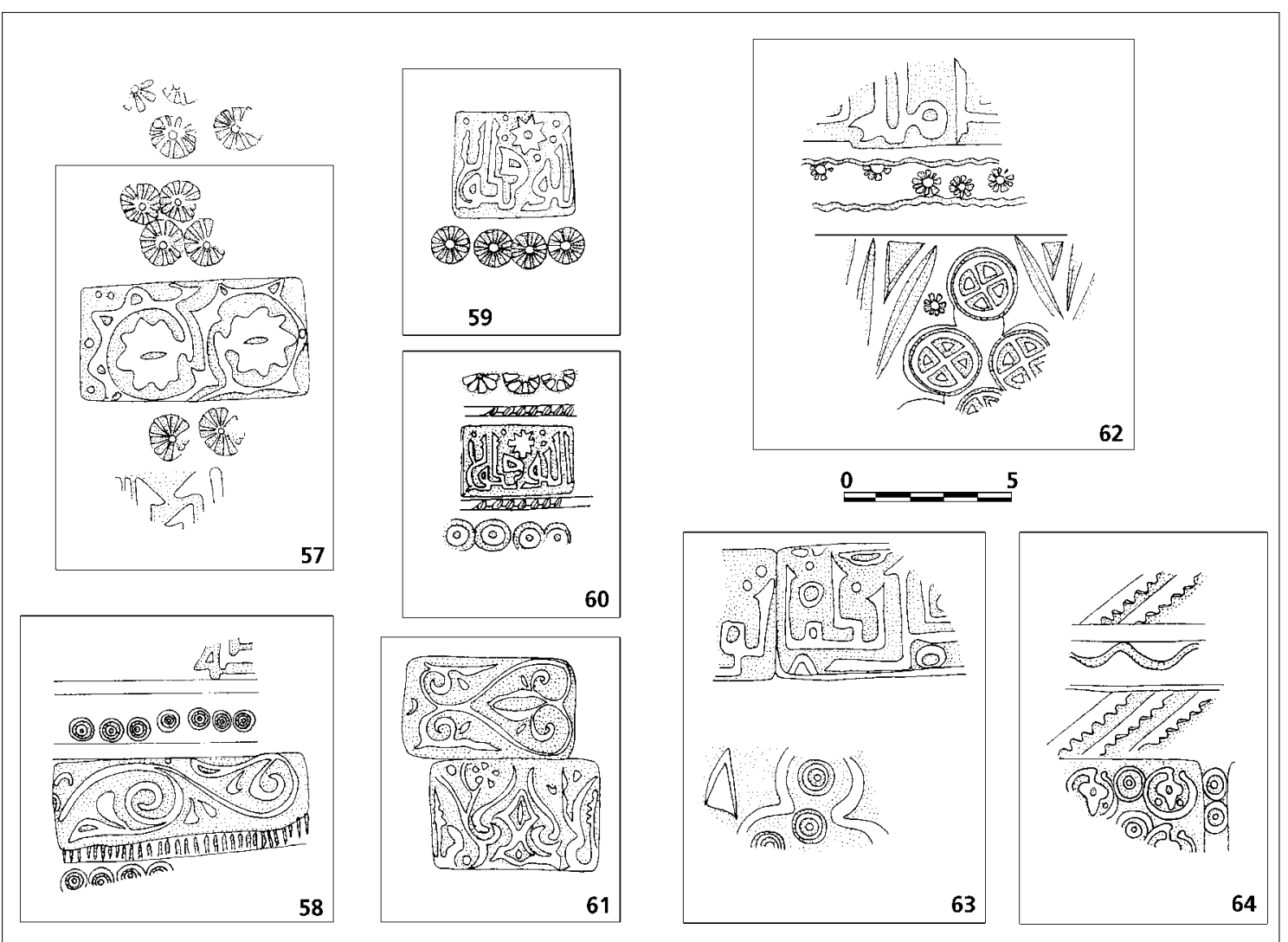

Fig. I5 


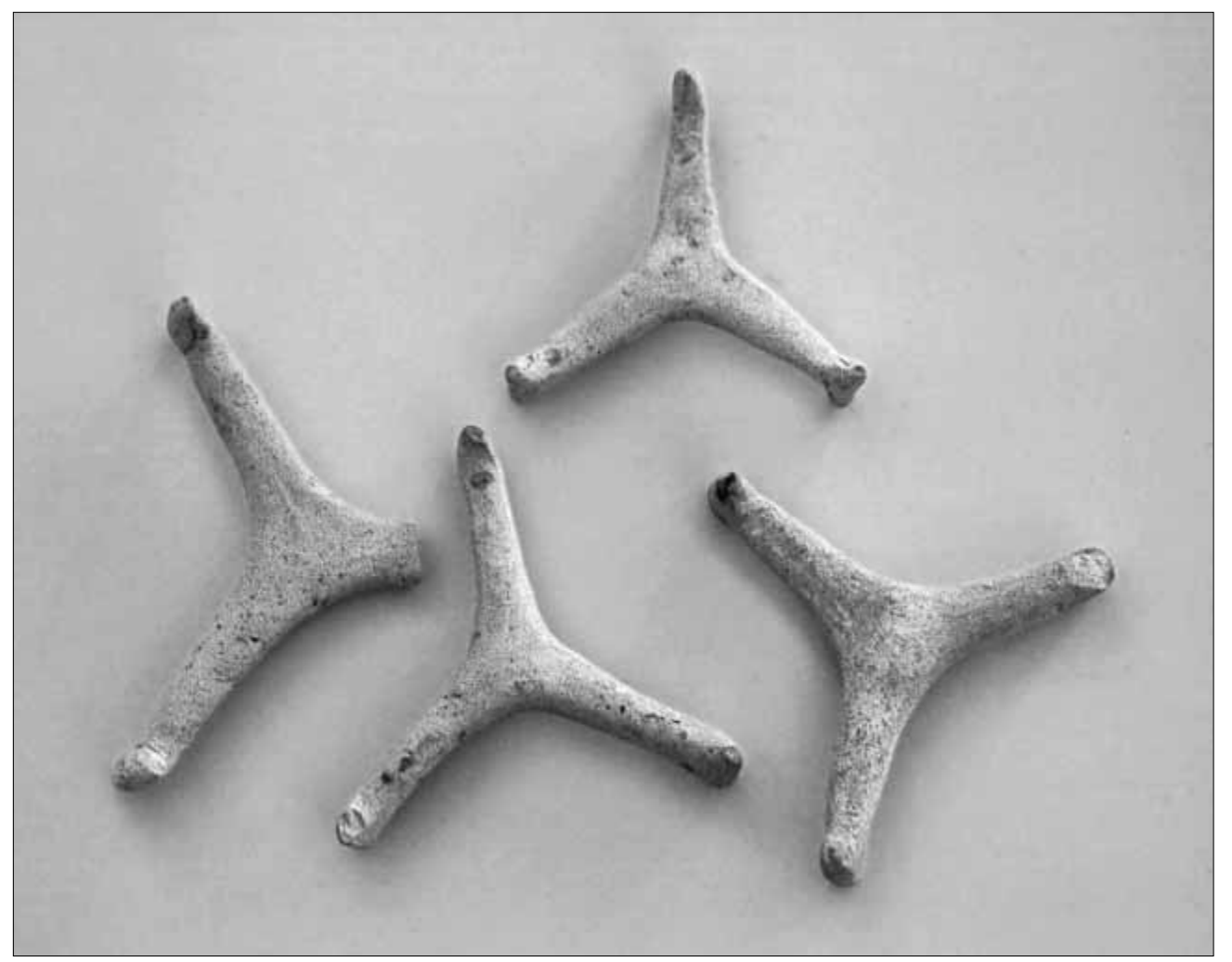

Lám. I. Trébedes

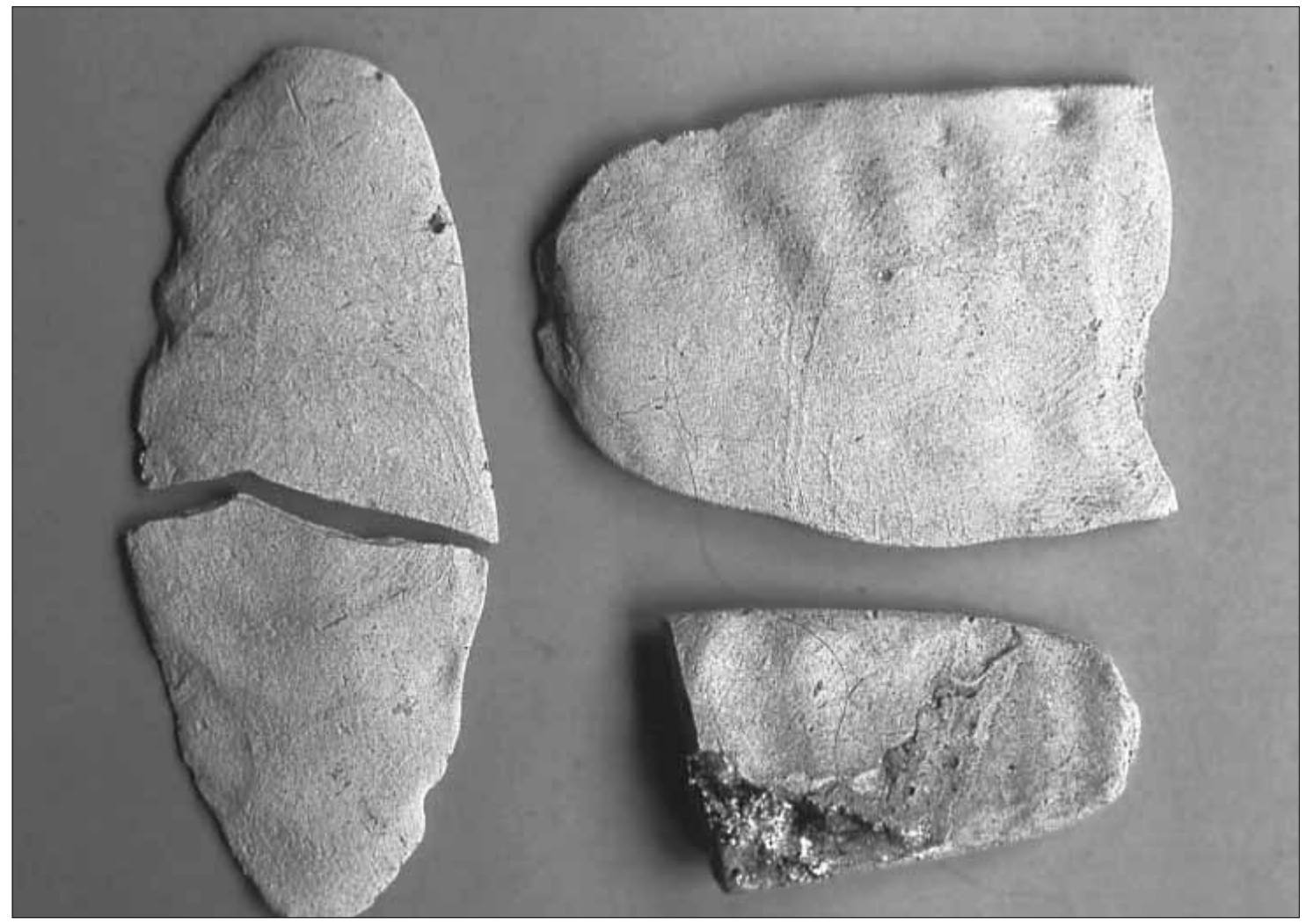

Lám. II. Lengüetas 


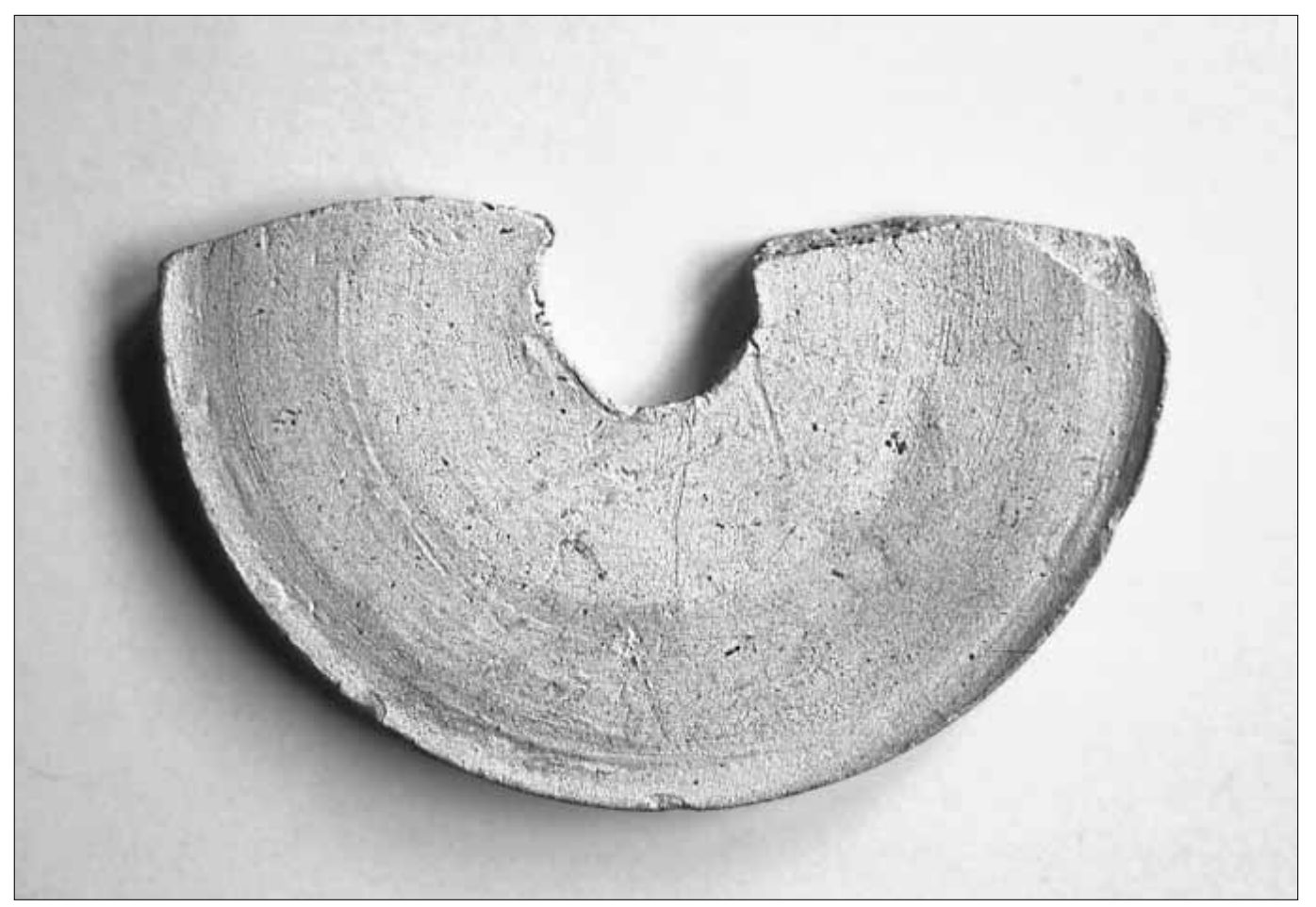

Lám. III. Anverso ¿Base de Jarra?

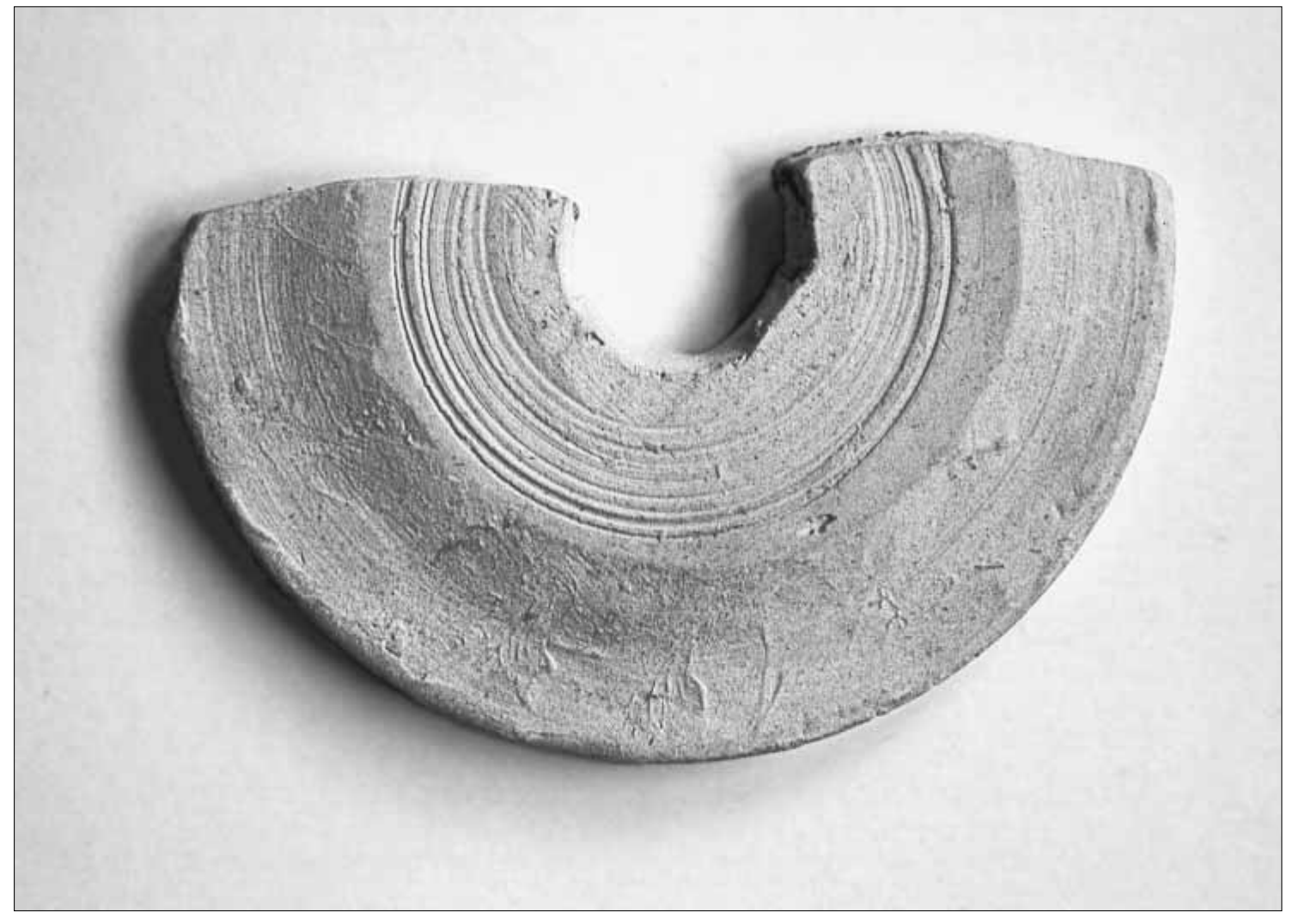

Lám. IV. Reverso ¿Base de Jarra? 


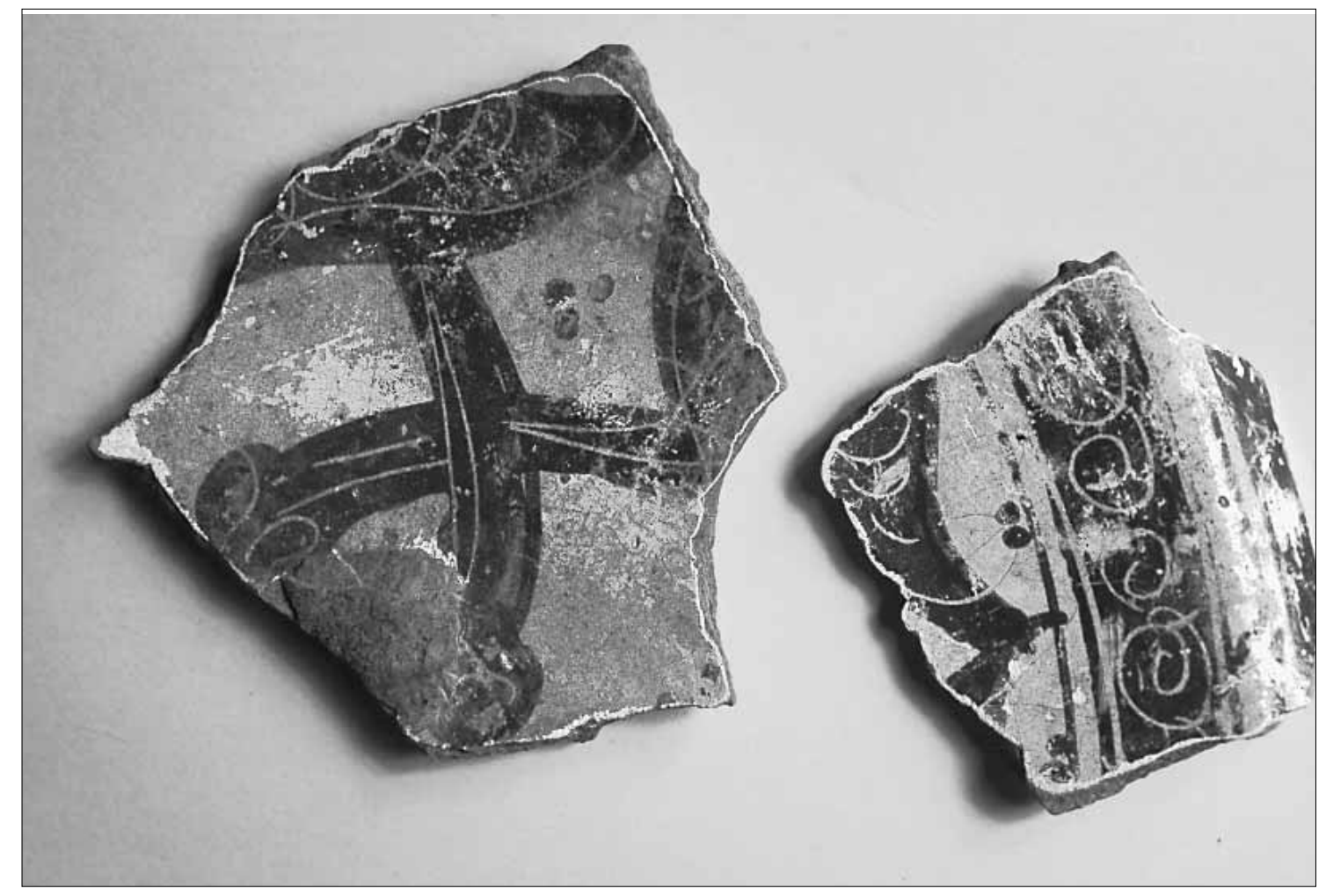

Lám. V. Fragmentos de loza dorado-esgrafiada procedente del alfar de la Terraza Imperial. Almería 